\title{
FLUJOS COMERCIALES \\ INTERCONECTADOS: EL MERCADO ASIÁTICO Y EL AMERICANO DURANTE LA SEGUNDA MITAD DEL SIGLO XVII
}

\author{
José Miguel Herrera Reviriego ${ }^{1}$ \\ Universitat Jaume I
}

n una carta dirigida a Felipe III en 1610, el presiden-
te de la Audiencia panameña, Francisco Valverde de
Mercado, ${ }^{2}$ se quejaba amargamente del elevado número
de textiles asiáticos que se hallaban en América, apuntan-
do lo perjudicial que resultaba su presencia tanto para su
propia jurisdicción como para las flotas llegadas desde Sevi-
lla, pues según sus palabras "los que van a emplear a Méxi-
co no podían sanear sus caudales si no truxeren la mitad de
su empleo en cosas de China, con lo qual biene a crecer
de manera que ganan abentajadamente de los que bienen a
emplear en las flotas en mercaderías de España". Al mismo

Fecha de recepción: 27 de agosto de 2014

Fecha de aceptación: 24 de agosto de 2015

${ }^{1}$ Este artículo deriva de la investigación de mi tesis doctoral "Manila y la Gobernación de Filipinas en el mundo interconectado de la segunda mitad del siglo xvII", Castellón de la Plana, Universitat Jaume I, 2014.

2 Bonialian, "La contratación de la China". 
tiempo remarcaba que a pesar de las restricciones impuestas a su trato en 1593, las mercancías asiáticas seguían fluyendo sin excesivo control por gran parte del Pacífico hispánico, ${ }^{3}$ afirmando que "el Pirú [está] todo lleno de ropa de China, Cartagena reciviendo las mercadurías, aviendo tiendas públicas en ella". ${ }^{4}$ Todo ello, mientras el número de textiles, muebles y otros productos asiáticos no dejaba de crecer en zonas tan dispares como México, Guadalajara, Guatemala, Panamá, Quito o Santo Domingo. ${ }^{5}$

Sin embargo, a pesar de esta buena situación de las mercancías asiáticas en territorio americano, su esplendor no perduró durante toda la centuria. Pues aunque su llegada se mantuvo de manera ininterrumpida en Nueva España, conoció un profundo estancamiento en el virreinato de Perú durante las décadas centrales del siglo Xvir.

Esta nueva coyuntura, aunque coincidió con la promulgación de diversas cédulas restrictivas con el comercio asiático y con distintos acontecimientos locales y regionales reseñables, también estuvo influenciada por varios movimientos producidos al otro extremo del océano Pacífico. De modo

${ }^{3}$ La preeminencia de actividades ilícitas, los informes parciales e interesados y la opacidad de las fuentes respecto de los flujos comerciales asiáticos y asiáticoamericanos imposibilitan la reproducción de estas corrientes mercantiles únicamente mediante la utilización de fuentes cuantitativas. Por esto es necesario apoyarse en las fuentes cualitativas para comprender la intensidad y vicisitudes de estos movimientos.

4 AGI, Panamá, 16, R. 2, N. 22. Carta de Francisco Valverde de Mercado, 25 de junio de 1610 .

5 AGI, Santo Domingo, 869, L. 6. Respuesta a carta de Diego Gómez de Sandoval, 20 de octubre de 1608. AGI, Quito, 9, R. 11, N. 80. Carta de Miguel de Ibarra, presidente de la Audiencia de Quito, 15 de abril de 1608 . 
que el decaimiento en la llegada de mercancías asiáticas a Lima coincidió con el surgimiento de una importante crisis mercantil en la Gobernación de Filipinas, en la que el número de productos exportables disponibles cayó en picada a medida que avanzaban las décadas. A su vez, esta crisis tuvo sus orígenes fuera de las fronteras de la propia Monarquía Hispánica, pues fue provocada principalmente por el surgimiento de diferentes movimientos de fondo generados en puntos tan diversos como China, India, Japón o Insulindia, los cuales acabaron trastocando intensamente los flujos comerciales del Asia marítima y repercutieron negativamente en el trato manileño, que a su vez arrastró consigo en su declive mercantil al floreciente tráfico de mercancías asiáticas que fluía por la vertiente americana del Pacífico.

Este intrincado y extenso entramado comercial de influencias y movimientos interrelacionados y polidireccionales se muestra como un claro reflejo de la profunda interconexión mercantil y económica existente entre dos regiones tan distantes como la América Pacífica y el Asia marítima, y de cómo, a pesar de presentar regímenes políticos, culturas y mentalidades diferentes, ambas zonas se sintieron directa o indirectamente afectadas por las alteraciones producidas en la orilla inversa del Pacífico. De modo que las épocas de bonanza en el mercado del Pacífico americano coinciden con el incremento del trato chino en el sureste asiático, mientras que las décadas en las que el flujo mercantil asiático con Filipinas sufrió mayores reveses, se solapan con los años de estancamiento del comercio entre Nueva España y Perú por la vía semiinformal del Pacífico. Puede apreciarse una serie de paralelismos entre las diferentes fases vividas por el comercio de mercancías chinas e indias en Asia y América 
durante el siglo XviI, así como advertirse la importancia que tuvieron algunas decisiones políticas en la alteración de estos flujos. De manera que imperios tan dispares como el hispánico, el chino y el mogol mostraron un grado de interconexión y vinculación mucho más elevado de lo que pudiera parecer en un primer momento debido a su posición geográfica.

Este intrincado y extenso proceso supera las barreras de análisis impuestas por el fenómeno de los estados nación, alejándose de las limitaciones “estatales” presentes en muchos estudios históricos tradicionales. ${ }^{6}$ A la vez, une diversos ámbitos temáticos y disciplinarios y muestra de qué manera interactuaban entre ellos, distanciándose de la parcelación excesiva de la historia ${ }^{7}$ y del desmigajamiento de la misma, ${ }^{8}$ mientras que se inserta dentro del proceso conocido como "primera globalización", 9 fenómeno que durante los albores de la Edad Moderna puso en contacto distintas regiones que hasta ese momento habían permanecido aisladas, permitiendo un fluido intercambio de personas, mercancías, ideas y conocimientos por gran parte del globo. ${ }^{10}$ Esta novedosa situación posibilitó que un sinfín de unidades locales y regionales, que hasta entonces se encontraban aisladas unas de otras, se vieran vinculadas entre sí en mayor o menor medida, de modo que los hechos acontecidos en uno de estos territorios, podían desencadenar una serie de cambios de cariz global, o por el contrario, un proceso de alcance mundial podía acabar afectando

\footnotetext{
6 Ballantyne, "Putting the nation in its place?", pp. 23-24.

7 Rojas, “Árboles, bosques y corsés”.

8 Elliot, "Comparative History".

9 Gunn, First Globalization.

10 Pomeranz y Topik, The World that Trade Created.
} 
a espacios locales y regionales teóricamente aislados. ${ }^{11}$ Estos postulados se recogen dentro de los principios compartidos por las distintas perspectivas de la "historia global", ${ }^{12}$ las cuales han profundizado en los estudios sobre la globalidad desde diversos enfoques, flujos o regiones. ${ }^{13}$

Por otra parte, todo este complejo entramado mercantil que puso en contacto tanto a los imperios chino, mogol, japonés e hispánico, como a las Provincias Unidas, el imperio “informal” portugués ${ }^{14}$ y un sinfín de reinos y regiones, y que creó un vasto espacio de influencias e interrelaciones mutuas, enlaza directamente con el enfoque histórico de la "historia conectada" propuesto por Sanjay Subrahmanyam ${ }^{15}$

${ }^{11}$ McNeill y McNeill, Las redes humanas.

12 Sachsenmaier, "Global Perspectives". Geyer y Bright, "World History".

${ }^{13}$ Para el Atlántico véanse CañIzares-Esguerra y Seeman, The Atlantic in Global History. Para África: Thorton, Africa and Africans; Gilbert y Reynolds, Trading Tastes. Para los océanos en general: Buschmann, Oceans in World History. Para el este y el sureste asiáticos: AndRAde, "A Chinese Farmer"; Wills, "Interactive Early Modern Asia”; GunN, History without Borders; Halikowski-Smith, "Globalisation before Globalisation"; Lockard, “The Sea Common to All”; Richards, "Early Modern India”; Tremml, "The Global and the Local”. Para la relación entre América y Asia: Flynn y Giraldez, "Born with a Silver Spoon"; Baena Zapatero, "Un ejemplo de mundialización"; Bonialian, El Pacífico hispanoamericano; Han, "La influencia del Galeón de Manila”; Martínez Shaw, "The Philippine Islands”; Oropeza Keresey, "La esclavitud asiática”.

${ }^{14}$ Andaya, "The Informal Portuguese Empire"; Souza, The Survival of Empire.

15 Subrahmanyam, "Connected Histories” y "Par-delà l'incommensurabilité”. 
y adoptado por Romain Bertrand, ${ }^{16}$ Serge Gruzinski ${ }^{17}$ e Eliga Gould, ${ }^{18}$ entre otros. ${ }^{19}$ En él se intenta ir más allá de la historia comparada, para extenderse dentro de un marco de relaciones más amplio, dedicado a estudiar las interconexiones mantenidas entre diferentes imperios y territorios, al mismo tiempo que defiende la existencia de vínculos culturales y económicos capaces de traspasar los límites impuestos por los estados nación para extenderse y englobar a distintas regiones y continentes. ${ }^{20}$

\section{EL ESPLENDOR DE LAS PRIMERAS DÉCADAS \\ DEL COMERCIO PACÍFICO}

En 1567, un Miguel López de Legazpi inmerso en plena conquista de las islas Filipinas, hizo partícipe a Felipe II de la importante vinculación comercial que la isla de Luzón mantenía con algunos de los países más importantes de la región, explicando en la misiva cómo llegaban hasta ella "los chinos y japones a contratar cada año”. A la vez, hacía partícipe al monarca del elevado potencial comercial que poseía este territorio, pues estos mercaderes que visitaban sus costas cada año portaban consigo "sedas, telillas, canpanas, porcelanas, olores, hierro, estaño, mantas de algodón pintadas y otras menuderías", ${ }^{21}$ productos muy valorados en América

\footnotetext{
${ }^{16}$ Bertrand, "Rencontres impériales” y L'Histoire à parts égales.

17 Gruzinski, "Les mondes mêlés".

18 Gould, "Entangled Histories".

19 Aslanian, From the Indian Ocean. Trivellato, The Familiarity of Strangers.

20 Subrahmanyam, "Connected Histories", pp. 759-762.

21 AGI, Filipinas, 6, R. 1, N. 7. Carta de Miguel López, Legazpi de 23 de julio de 1567.
} 
y Europa y de los que se podían obtener grandes beneficios. Así, no es de extrañar que durante los meses siguientes tropas de Legazpi dirigieran su mirada hacia el norte, iniciando la conquista de gran parte de la isla de Luzón y estableciendo el centro del poder hispánico en la ciudad de Manila, urbe que sería fundada en 1571 sobre un importante emplazamiento indígena. ${ }^{22}$

El establecimiento y consolidación de la Monarquía Hispánica en el norte del archipiélago produjo una intensificación sin precedentes del trato asiático en la región. Los comerciantes chinos se sintieron profundamente atraídos por las grandes cantidades de plata americana que los hispánicos portaron consigo, pues la demanda de este metal en el continente era mucho más elevada que la de oro y productos agrícolas que tradicionalmente adquirían de los indígenas. ${ }^{23}$ De este modo, durante los siguientes años un creciente número de mercaderes procedentes de Guangdong y Fujian se acercaron hasta Manila con el objeto de intercambiar textiles, mobiliario y porcelana ${ }^{24}$ por metal argénteo, fomentándose intercambios en que tanto chinos como hispánicos resultaban beneficiados. Así pues, los chinos consiguieron una vía de acceso alternativa a la japonesa para la obtención de plata, metal que presentaba gran demanda en el seno del

\footnotetext{
22 Bascara y Foronda, Manila.

23 "Y el retorno que llevan es oro y cera." AGI, Filipinas, 6, R. 1, N. 7. Carta de Miguel López de Legazpi, 23 de julio de 1567.

24 "Y fuera de estas sedas, todo quanto traen son bujerías de que ningún provecho viene a la tierra, porque no son sino porcelanas, escritorzillos y cazuelas y ventalles y tirasoles, y de ningún provecho. Y no se puede contratar con ellos sino con oro y plata." AGI, México, 20, N. 3. Carta del virrey de México Martín Enríquez, 20 de marzo de 1580.
} 
imperio de los Ming, producida por su propio sistema económico e impositivo y por su escasa extracción interna. ${ }^{25}$ Mientras que por su parte, los hispánicos obtenían del trato con los chinos grandes cantidades de mercancías asiáticas a muy bajo coste, las cuales resultaban sumamente competitivas en los mercados indianos, ${ }^{26}$ rivalizando con productos europeos como las sedas y tafetanes. ${ }^{27}$ Además, la escasa regulación legislativa y tributaria existente respecto a este tipo de trato ${ }^{28}$ hizo que los beneficios obtenidos durante esta época fueran todavía más elevados, ${ }^{29}$ animando a muchos inversores a apostar sus capitales en el tráfico transpacífico. Por esto, los intereses comerciales acabaron rompiendo definitivamente las barreras geográficas que hasta entonces habían separado Asia de América, y durante los años siguientes a la conquista de Luzón, un creciente número de

25 Flynn y Giraldez, "China and the Spanish Empire”, pp. 309-338.

26 "Las ganançias de la contratación de la China son tan elevadas." AGI, Quito, 9, R.11, N. 82. Autos y diligencias efectuados por el oidor Diego de Armenteros y Henao el 15 de abril de 1608.

27 "Los mercaderes sienten mucho lo que viene de las islas, porque aunque los rasos que de allá vienen y los damascos y otras sedillas, y aun las más finas, son de muy poca seda y otras texidas con hierva, que todo es muy valadí. Al fin el barato haze bajar las sedas que vienen de España, sino son los terçiopelos, porque de allá no los traen, y an llegado los tafetanes de España a no valer más que a ocho reales y los reales damascos an bajado mucho y teme que yendo esto adelante no avrá para que traer rasos ni tafetanes ni damascos de España”. Carta del virrey de México Martín Enríquez, 20 de marzo 1580. AGI, México, 20, N. 3.

28 Yuste López, "De la libre contratación".

29 "Y que por serle primer subceso lo que se trae no han pagado almojarifazgo.” AGI, México, 19, N. 116. Carta del virrey de México Martín Enríquez, 1573. 
navíos decidieron cruzar el Pacífico desde Nueva España y Perú con rumbo a Manila y Macao. ${ }^{30}$

El aumento de la intensidad comercial entre ambos continentes no pasó desapercibida para las autoridades madrileñas, ${ }^{31}$ quienes vieron en él un auténtico obstáculo para el sistema de flotas, puesto que su auge debilitaba la posición de las mercancías europeas en América ${ }^{32}$ y permitía que los dos grandes virreinatos se retroalimentaran mutuamente por el Pacífico. ${ }^{33}$ Además, suponía un desafío para las finanzas del imperio español, pues el fomento del tráfico mercantil con Asia estaba provocando en último término una huida masiva de capitales en dirección a China, imperio sobre el que incluso se había tanteado la posibilidad de una intervención militar. ${ }^{34}$

En 1593, solo unos años más tarde de iniciarse el tráfico transpacífico, desde Madrid se hizo pública una real cédula destinada a limitar, acotar y estructurar en la medida de lo posible las nuevas rutas comerciales surgidas tras la conquista de Filipinas. De este modo, se estableció a Manila y a Acapulco como los únicos puntos de unión legales entre ambos continentes, a la vez que se restringía el tráfico entre estos dos puertos a un viaje por año. En la práctica, se reservó para Nueva España el monopolio de la recepción del galeón filipino y del

30 "Dieron nuevas que a la ciudad de Macán avía llegado un navío del Pirú con mucha plata para emplear en mercaderías." AGI, Filipinas, 18A, R.7, N.47. Carta de la Audiencia de Manila, 13 de julio de 1589.

31 Alonso Álvarez, "E la nave va".

32 AGI, México, 20, N. 3. Carta del virrey de México Martín Enríquez, 20 de marzo 1580.

33 Bonialian, El Pacífico hispanoamericano, p. 53.

${ }^{34}$ Ollé, La empresa de China. 
contacto directo con Asia, prohibiendo a peruanos, guatemaltecos ${ }^{35}$ y panameños dirigir sus embarcaciones rumbo al archipiélago, como habían hecho hasta el momento. ${ }^{36}$ Estas restricciones no solo abarcaron la navegación, sino que también alcanzaron al propio comercio indiano, puesto que en ellas se vetó explícitamente el traslado de mercancías manileñas a Perú, Guatemala, Tierra Firme o cualquier otro lugar de América. ${ }^{37}$

El balance del cumplimiento de la real cédula de 1593 fue más bien ambivalente, pues resultó más eficaz a la hora de regular el tráfico de embarcaciones que el propio mercado interno americano; si bien las normativas relacionadas con los galeones se siguieron casi sin fisuras, no se consiguió el mismo grado de eficacia a la hora de detener la expansión de mercancías asiáticas por el Pacífico americano. Así, los mercaderes mexicanos siguieron trasladando sin excesivas trabas grandes cantidades de los textiles chinos hasta Guatemala y el mar Caribe. ${ }^{38}$ Mientras, los comerciantes peruleros continuaron con sus viajes hasta Acapulco, adquiriendo importantes remesas de productos asiáticos en sus ferias para su posterior traslado a los mercados meridionales, todo ello con el conocimiento de los oficiales reales y a pesar de que estas prácticas se encontraban formalmente prohibidas. ${ }^{39}$

35 Yuste López, "De la libre contratación”.

36 Bernal, "La carrera del Pacífico", pp. 485-545.

37 Yuste López, "El dinamismo rutinario", pp. 211-212.

38 AGI, Santo Domingo, 869, L. 6. Respuesta a la carta de Diego Gómez de Sandoval, 20 de octubre de 1608.

39 "Los offiçiales reales de la çiudad despachan públicamente y admiten y haçen registros de mercaderías y sedas de China, y entran navios cargados de ellas y tampoco se proybedo este trato ante han estado las tiendas aviertas”. AGI, Panamá, 16, R. 1, N. 14. Carta del fiscal de Panamá Bartolomé Morquecho, $1^{\circ}$ de octubre de 1609. 
Pero la influencia de las conexiones comerciales de los mercaderes peruleros no sólo se extendió por América, pues en su búsqueda de productos asiáticos a bajo coste, incluso llegaron a asentar a sus delegados y personas de confianza en las propias islas Filipinas para evitar la intermediación mexicana. ${ }^{40}$ De modo que en la práctica, gran parte de las regulaciones de 1593 quedaron en mero papel mojado, y los productos asiáticos siguieron recorriendo y dispersándose por territorio indiano sin excesivos problemas, como quedaría reflejado en las palabras del oidor de la Audiencia de Quito, Diego de Armenteros, quien en 1608 afirmó que "sin embargo de lo contenido en dicha cédula [...] no se an dexado de llevar y llevan todavía de la dicha Nueva España y se gastan las dichas provincias del Perú y Tierra Firme, Quito y Nuevo Reyno de Granada mercadurías de China con mucho exçesso" ${ }^{41}$ Estas normativas también fracasaron en sus objetivos iniciales de reforzar la posición de los productos europeos en el mercado americano y de evitar una retroalimentación comercial entre Nueva España y Perú por el Pacífico, por lo que aquellos territorios como Panamá, que

40 "Y así gozan peruleros y mexicanos del aprovechamiento que vuestra magestad ha concedido a los vezinos de las yslas." AGI, Filipinas, 6, R. 9, N. 178. Carta del gobernador de Filipinas Tello, 6 de julio de 1601. "A peruleros, con cargo de que hiziessen vezindad en estas yslas çierto tiempo [...] de que se a seguido notable daño, pued demás de estar ympedidos de hacerse de su hazienda, los peruleros es gente gruesa binieron cargados de dinero por registrar. [...] Y así cargaron los peruleros las naos y el provecho de vuestra magestad que avían de tener los vezinos de estas yslas lo vienen a gozar los peruleros.” AGI, Filipinas, 6, R.9, N. 167. Carta del gobernador de Filipinas Tello, 12 de julio de 1599.

${ }^{41}$ AGI, Quito, 9, R. 11, N. 82. Autos y diligencias efectuados por el oidor Diego de Armenteros y Henao el 15 de abril de 1608. 
mantenían una estrecha relación con el sistema de flotas, se vieron severamente afectados por la incapacidad de la cédula de 1593 para detener la proliferación de este circuito semiinformal de mercancías asiáticas por el Pacífico. De modo que incluso el presidente de la Audiencia panameña, Francisco Valverde de Mercado, achacó los problemas que venía sufriendo su jurisdicción a la presencia de textiles asiáticos en la zona y al comercio directo mantenido entre Nueva España y Perú, no dudando en pedir al monarca que detuviera este tipo de intercambios lo antes posible y que ordenara quemar toda la ropa que llegara desde China. ${ }^{42}$

\section{LA CAÍDA TRAS EL ESPLENDOR. MOVIMIENTOS ASIÁTICOS} Y REPERCUSIONES AMERICANAS A MEDIADOS DEL SIGLO XVII

A comienzos del siglo XVII, el flujo de mercancías asiáticas hasta América parecía ilimitado, y como tal se entendió hasta hace pocos años por gran parte de la historiografía, que vio a los movimientos comerciales asiáticos como meros sujetos pasivos, como una corriente constante e inagotable capaz de absorber toda la demanda requerida por galeones transpacíficos y por los grandes hombres de negocios

42 “Ni oy conozco este reino, porque beó los V.S del pobres llenos de travajos y neçesidades muchas, casas despobladas y las demás tan flacas en el tratrato $[s i c]$ de ellas que se hecha muy bien de ver que va padeçiendo ruina. Y si Vuestra Magestad, con su poderosa mano no lo remedia estorvando la contrataçión de la China con el Pirú por la Nueva España y la propia contratación con los demás reinos de estas Yndias, como lo tengo ferito a Vuestra Magestad desde México. [...]. Por lo que a mí me tocase aseguro a Vuestra Magestad que sirviéndose de mandar que se queme la rropa de China, aunque sean cosas caseras.” AGI, Panamá, 15, R. 7, N. 58. Carta de Francisco Valverde de Mercado, 30 de enero de 1606. 
mexicanos y peruanos. Pero realmente, y al contrario de la creencia tradicional, el tráfico asiático con Luzón no siempre pudo mantener unos niveles de oferta estables y adecuados a la demanda americana, o al menos no fue capaz de hacerlo durante gran parte del siglo Xvir, debido a que el flujo comercial filipino se vio afectado por una serie de vicisitudes tanto internas como externas. Así pues, tras un boyante y esplendoroso siglo xvi y de un esperanzador comienzo del XVII, la corriente de intercambios entre Filipinas y los diferentes puertos mercantiles presentes en el continente dio un drástico vuelco, azuzado por diversos cambios políticos acontecidos tanto en Asia como en otros puntos del globo.

Uno de los principales focos de este cambio fue precisamente el imperio chino, con el cual Filipinas mantenía una intensa vinculación que fue estrechándose a medida que transcurrían las décadas. ${ }^{43}$ La economía de las élites hispánicas acabó perfilándose siguiendo el devenir del comercio chino, dedicándose sus miembros principalmente a la tarea de reexportar sus mercancías hasta América y a cobrar los beneficios de su venta en Acapulco. Mientras, la presencia hispánica en Asia atrajo a un elevado número de población china hasta Manila y sus aledaños, que acabó vertebrando la organización del territorio filipino, así como dotándolo de una entidad particular. ${ }^{44}$ Por ello, no es de extrañar que los cambios y tendencias acontecidos en el seno del imperio Ming

43 García-Abásolo, "Los chinos y el modelo colonial”; Gil, Los chinos en Manila; Ollé, "La formación del Parián de Manila”.

44 "La Alcaycería que llaman 'Parián de los sangleyes', y es chinas [sic], que asisten en sus extramuros, necesarios para la conservación y el sustento de estas yslas." AGI, Filipinas, 285, N. 1. Carta de Sabiano Manrique de Lara sobre materias militares, 19 de julio de 1654. 
acabaran provocando profundas alteraciones en el comercio, economía y sociedad filipinas, que a su vez repercutieron tanto en el tránsito transpacífico como en el tráfico americano de mercancías asiáticas. Así pues, no resulta sorprendente que el declive del comercio entre Filipinas y América coincidiera temporalmente con el surgimiento de importantes acontecimientos en China, tales como el colapso y la caída de la dinastía Ming, el alzamiento y consolidación de la Qing y el surgimiento de la familia Zheng. Por lo que para encontrar los orígenes del descenso de la circulación de mercancías asiáticas en el circuito comercial del Pacífico americano, hay que dirigir la mirada más allá de los límites de la propia Monarquía Hispánica, hacia la lejana China.

Durante las décadas iniciales del siglo xvir, la dinastía Ming certificó la crisis de autoridad en la que se encontraba sumergida durante los últimos años, mostrándose incapaz de mediar en las confrontaciones cortesanas, de evitar el surgimiento de importantes poderes autónomos en el sur y de acabar con el descontento que se extendía por el norte. Toda esta inestabilidad interna acabó generando una profunda conflictividad en el seno del imperio que explotó dramáticamente en 1644 con la caída de Beijing en manos del rebelde Li Zicheng y con el suicidio del último emperador Ming. El vacío de poder resultante no pasó desapercibido para los manchúes situados al norte, ${ }^{45}$ quienes acabaron conquistando Beijing sin dificultades pocas semanas después de cruzar la frontera china. Con la "capital del norte" bajo su control, los manchúes establecieron a sus propios mandatarios en el trono imperial en sustitución de los Ming, alzándose

${ }^{45}$ Dennerline, “The Shun-Chih Reign”, p. 80. 
una nueva dinastía en el poder, la Qing, que se mantendría al frente de China hasta el siglo xIx.

A pesar de la rapidez con la que los manchúes tomaron Beijing, la conquista de la capital no conllevó una subordinación inmediata y automática del conjunto del imperio, puesto que los Ming aún conservaban numerosos apoyos internos, alentados en parte por la visión negativa que muchos de los chinos tenían de sus nuevos mandatarios, a quienes veían como extranjeros usurpadores alejados de sus costumbres y tradiciones. De este modo, los desafíos a la nueva dinastía no tardaron en aparecer, surgiendo numerosas voces discordantes a lo largo y ancho de China, de entre las que destacó por encima de las demás la de la familia talasócrata de los Zheng, quienes se declararon fieles a los Ming y se opuseron a reconocer la nueva dinastía. ${ }^{46}$

El desafió de los Zheng a la nueva dinastía no era un asunto menor para los manchúes, pues esta saga familiar era mucho más que un simple poder autónomo surgido en el sur del imperio que albergaba un potencial económico y militar suficiente para rivalizar con los recién instaurados Qing. ${ }^{47}$

46 "Sucedió pues en el mes de febrero de 1653, que subieron inopinadamente por el río de Togan más de ochenta champanes de chinos, que con título de fieles al legítimo emperador de China molestaban como piratas del mar y la tierra." Fragmento del libro Hechos de la Orden de Predicadores en el Imperio de China de Victorio Riccio. APSR, China, sec. 34, t. 2, lib. 2.

47 "El día 17 de junio de 1660 y opestesele el Cogsenya con su armada, y dándose vista antes del amanezer.

Con tanto brio comensaron a batallar, haciendo cada uno por su partte grandes esfuerzos, peleando más de 1200 baxeles de guerra de ambas partes, la mayor del Tártaro, poniendo en confución a los que de tierra la miraban. El estruendo de la artillería y el ruido de las voces de los ynstrumentos bélicos y alaridos hechos humo, que mandó unos echando a pique, otros 
La cabeza de esa familia, Zheng Zhilong, ${ }^{48}$ fue todo un ejemplo de la superación personal pues pasó de ser un simple trabajador portuario de Manila y Macao durante su juventud, ${ }^{49}$ al líder de toda una red de navíos, que contaba con miles de personas a su servicio y con representantes en los más importantes puertos del este y sureste asiáticos. Dicho potencial naval permitió a esta familia de talasócratas conseguir unos fiables canales de financiación gracias a la combinación de prácticas comerciales y piráticas ${ }^{50}$ que la convirtieron en uno de los principales intermediarios tanto con Japón como con Filipinas, los dos principales focos exportadores de plata del continente. Por lo que para los Zheng no fue demasiado difícil enrolar en sus filas a un nutrido grupo de hombres que iban desde wokou hasta lealistas Ming, y que los dotaron de una fuerza y pujanza inusitadas. La pugna militar entre Qing y Zheng por el control del espacio marítimo del sureste chino tuvo proporciones enormes que asombraron a los gobernadores filipinos ${ }^{51} \mathrm{y}$ en las que se combinaron

saliendo en rretirada en profunda orden, se bia un desordenado remolino de desdichados llantos y muertes a fuego y sangre con gran espesura de balas y flechas que disparavan repetidamente a menudo." AGI, Filipinas, 9, R. 2, N. 34. Carta de Sabiniano Manrique de Lara, 20 de julio de 1661. ${ }^{48}$ Conocido en las fuentes hispánicas como Iquan, Icoan, Nicolás Icoan o Nicolas Iquan, además de una larga serie de formas análogas.

49 "Este fue tan pobre que por no perecer de hambre pasó a esta ciudad de Manila [...] y vivió en el Parián, extramuros de ellas, haciendo oficio de corredor o regatón". Breve historia de Iquam y Koxinga, publicada en Manila en 1662, Archivo del Ateneo de Manila. Borao Mateo, Spaniards in Taiwan, pp. 580-585.

50 Andrade, “The Company's Chinese Pirates".

51 AGI, Filipinas, 9, R. 2, N. 34. Carta de Sabiniano Manrique de Lara, 20 de julio de 1661. 
los enfrentamientos navales, las batallas terrestres y los asedios prolongados.

Los efectos de la pugna mantenida entre las dos facciones chinas no fueron ajenos a Filipinas pues acabó provocando importantes problemas para la actividad comercial de Manila. Las provincias de Fujian y Guangdong, que a la sazón monopolizaban la mayor parte del contacto mercantil chino con Luzón, se vieron arrastradas en la vorágine de la guerra, por lo que el número de juncos chinos que atracaron en la ribera del Pasig durante estos años se vio severamente reducido, ${ }^{52}$ mientras que la calidad y cantidad de las mercancías transportadas quedó en entredicho. Pero ésta no sería la etapa más dura vivida por el tráfico mercantil sinofilipino, ya que por desgracia para los intereses mercantiles manileños, con el encarcelamiento de Zheng Zhilong en Beijing y el ascenso al frente de la familia de su hijo Zheng Chenggong, ${ }^{53}$ las confrontaciones en China no hicieron más que aumentar en volumen y en virulencia. ${ }^{54} \mathrm{~A}$ su vez, la

52 "El comercio que tanto importa a estas islas con los de China, que cuando llegué hallé cortado y quebrado con el acçidente de las guerras que tienen tártaros con los que siguen la voz y séquito del Cogsen Ponpuán.” AGI, Filipinas, 9, R. 3, N. 50. Carta de Diego Salcedo, 4 de julio de 1667.

${ }^{53}$ Conocido en las fuentes hispánicas como Koxinga, Cuesing o distintas formas análogas.

54 "Estaba por estos tiempos tan poderoso y formidable en la mar el Cuesing, que ponía terrror a toda la China, pero como no podía penetrar mucho por la tierra adentro, todos los daños que hacía entonces era en lugares marítimos. Por el fin, pues, de año de 1656, celebrándose el cuarto domingo de adviento, entraron por la ensenada del mar y por los ríos de Togán más de tres mil champanes del Cuesing entre grandes y pequeños". Fragmento del libro Hechos de la Orden de Predicadores en el Imperio de China de Victorio Riccio. APSR, China, sec. 34, t. 2, lib. 2. 
fuerte personalidad de este mestizo de chino y japonesa acabó generando una serie de conflictos diplomáticos y mercantiles con Manila, los cuales redujeron e incluso cortaron el trato con las provincias chinas durante algunos meses. Así pues, entre los años 1656 y 1657, Zheng Chenggong, harto de los altos impuestos y el trato recibido por sus navíos en Filipinas, prohibió los intercambios entre los territorios bajo su dominio y Luzón. ${ }^{55}$ En 1662, el talasócrata chino exigió el pago de un tributo a la Gobernación hispánica, que al no ser atendido dio lugar a una declaración de guerra por parte de los Zheng, amenaza que tuvo gran impacto para la población europea y americana asentada en el archipiélago, pues todavía permanecía fresca en la memoria de los manileños la conquista a sangre y fuego que el talasócrata había acometido en la neerlandesa Formosa, tan solo unos años atrás. A su vez, esta declaración de guerra tuvo un efecto nefasto tanto para el comercio como para las finanzas de las islas; paralizado el trato chino, provocó importantes levantamientos en el Parián y emplazó a la Gobernación a acometer una serie de reformas militares que la Real Hacienda filipina no podía costear. Para fortuna de los intereses hispánicos, el ataque chino fue cancelado en el último momento por la repentina muerte de su mandatario, siendo reconsiderado el ataque

${ }^{55}$ Prohibió, bajo pena de muerte, que nadie osase pasar a las Filipinas ni tener correspondencia con los españoles, por ser (como decía él) hombres soberbios, codiciosos, coléricos, descorteses, despreciadores de toda nación y que no pagan lo que en nombre del rey compran y que continuamente vejan con intolerables insultos, heridas y muertes a sus vasallos que van al comerzio o que viven en aquellas yslas". Fragmento del libro Hechos de la Orden de Predicadores en el Imperio de China de Victorio Riccio. APSR, China, sec. 34, t. 2, lib. 2. 
por su hijo Zheng Jing, quien presentó un talante más conciliador con Manila y que entendió la importancia que la plata mexicana tenía para la financiación de su entramado militar mercantil.

Mientras las relaciones entre Manila y los Zheng empeoraban, la guerra continuaba en el litoral chino y los Qing, hastiados de la confrontación directa contra la familia de talasócratas, en 1660 decidieron cambiar su estrategia bélica, reencaminándola hacia un progresivo debilitamiento de la principal fuente de adquisición de recursos de los Zheng, el comercio. Para ello, el emperador emprendió la fortificación del litoral, prohibió el comercio marítimo y expidió un decreto que obligaba a todos los habitantes de la franja costera a abandonar sus hogares y a desplazarse entre 15 y $30 \mathrm{~km}$ tierra adentro, suponiendo esta normativa un auténtico cataclismo para la China marítima y su actividad mercantil. ${ }^{56}$

De igual forma, y a pesar de la dureza de las ordenanzas imperiales, la exportación de géneros chinos no cesó, encontrando diversos subterfugios y caminos secundarios por los que desviar sus tejidos y porcelanas a los mercados internacionales, no obstante el volumen y la calidad de los productos comercializados cayó drásticamente, por lo que esta

56 "Por la cual hicieron una determinación, la más cruel y bárbara que se havido en historias. Mandaron so pena de muerte que se despoblase toda la orilla marítima de China que tiene de longitud más de ochocientas leguas (pues comprehende cuatro provincias) donde eran innumerables los pueblos y lugares. Ordenando que todos se entregasen al fuego sino quisieren retirarse dentro de la tierra, apartados del mar tres y cuatro leguas. Prohibiendo todo género de embarcación, aun para pescadores, mandándolas desfondar y hacer pedazos". Fragmento del libro Hechos de la Orden de Predicadores en el Imperio de China de Victorio Riccio. APSR, China, t. 2, lib. 3. 
situación supuso un fuerte revés para el comercio manileño, que vio limitada la adquisición de mercancías chinas a los productos que los Zheng les pudieran suministrar desde su base en Taiwán. Esto provocó a su vez una importante caída en la llegada de géneros asiáticos hasta América, como se puede apreciar en los almojarifazgos documentados en Acapulco durante estos años ${ }^{57}$ o en los registros de los juncos llegados a Manila. ${ }^{58}$ De modo que de los 239822 pesos recaudados por el almojarifazgo de los navíos chinos durante la década de 1630, se pasó a 125503 pesos durante la de 1640, disminuyendo durante la década de 1650 hasta los 35894 y 21473 en la de $1660 .{ }^{59}$ A su vez, toda esta conflictividad también provocó un cambio en la tipología de las mercancías llegadas hasta la ribera del Pasig, pues los ricos damascos y tafetanes, así como la seda cruda que otrora inundaron las bodegas de las naos transpacíficas, fueron sustituidos por tejidos más sencillos y baratos fabricados principalmente a base de algodón, los cuales eran transportados por comerciantes chinos desde diferentes puntos de China, Japón y Cochinchina. ${ }^{60}$

Pero la caída comercial derivada de los problemas internos del imperio chino no fue la única adversidad a la que tuvo que hacer frente Manila, pues durante estos años Filipinas conoció una progresiva pérdida de sus mercados. Así pues, la prohibición a los manileños de comerciar con Japón en 1624 y a los lusos en 1639, le siguió la separación de Portugal de la

\footnotetext{
57 Calderón, Historia económica de la Nueva España, p. 577.

58 AGI, Filipinas, 64, N. 1.

59 AGI, Filipinas, 24, R. 2, N. 14. Informes sobre la recaudación del almojarifazgo.

60 FANG, El comercio entre los sangleyes y Luzón.
} 
Monarquía Hispánica, situación que tuvo profundas consecuencias para la Gobernación asiática, pues los mercaderes filipinos habían desarrollado fuertes lazos con Macao, que se vieron cortados de manera súbita y sumamente traumática. De esta manera la separación de coronas provocó una serie de tensiones entre las dos ciudades y generó un descenso en la cantidad de mercancías llegadas desde el Estado da India hasta Manila. ${ }^{61}$

Aunque tras los primeros años de la década de 1640 los intercambios entre lusos e hispánicos en Asia se detuvieron casi por completo, las necesidades mutuas acabaron por tender puentes, desviándose parte del trato lusomanileño hacia diferentes entrepôts del continente, como Macasar, donde los comerciantes podían hacer negocios en común sin exponerse públicamente.

Por su parte, la presencia de las Provincias Unidas en Asia también tuvo importantes consecuencias para la llegada de productos asiáticos a Manila, pues la Guerra de los Ochenta Años, a pesar de tener un origen puramente europeo, acabó ramificándose hasta el Pacífico occidental, generando una serie de reveses para los intereses de la Monarquía en el continente. De este modo, los neerlandeses, concentrados en sus posiciones de Taiwán y Batavia, se dedicaron durante buena parte de la primera mitad del siglo xvir a acosar y saquear, solos o con la ayuda de diversos piratas sinojaponeses, las naves hispánicas o los juncos chinos que se desplazaban hasta Luzón. ${ }^{62}$ Todo ello mientras mantenía un importante

61 "Y con todo se comensava ya sentir necesidades en estas islas con solo aver faltado el de la Yndia y Macán con el alçamiento de Portugal.” AGI, Filipinas, 9, R. 1, N. 13. Carta de Diego Fajardo, 4 de junio de 1650.

${ }^{62}$ Andrade, “The Company’s Chinese Pirates", pp. 295-321. 
cerco al territorio filipino, realizando distintos ataques sobre Manila, sus provincias cercanas e incluso sobre los galeones transpacíficos. ${ }^{63}$ Por ello, la intervención de las Provincias Unidas en el Pacífico acabó generando una situación de inseguridad en torno al comercio manileño, incidiendo en última instancia en el volumen del tráfico mercantil llegado hasta la ciudad filipina y en los recursos disponibles para la exportación.

Todas estas alteraciones, producidas en Asia entre las décadas de 1630 y 1640, no fueron movimientos solo de alcance regional o continental, sino que acabaron repercutiendo directamente en Nueva España y en otros territorios, tanto de América como del resto del globo. El descenso en la introducción de mercancías en Manila, producido en buena medida por estos movimientos, conllevó a su vez una reducción de la oferta en la feria de Acapulco, provocando que los productos embarcados en los galeones resultaran insuficientes para satisfacer los niveles de demanda que el comercio americano había presentado durante las décadas anteriores. Además, la práctica desaparición de los textiles de seda de los juncos chinos ${ }^{64}$ pudo producir un cambio en el modelo de consumidor asociado al comercio oriental, siendo éste menos interesante para las clases altas americanas, ávidas de textiles delicados y lujosos, las cuales en muchos casos pudieron focalizar su interés en los productos transportados desde la península ibérica. Por lo que no es de extrañar que durante estos años, y al contrario de lo que ocurrió en décadas anteriores, durante los años centrales del siglo xviI,

63 Blumentritt, Filipinas. Ataques de los holandeses, pp. 45-59.

64 AGI, Filipinas, 64, N. 1. Informes de los registros de navíos. 
los flotistas no consideraron las mercancías llegadas de Asia como una competencia real de sus manufacturas, argumentando que las sedas chinas no eran excesivamente numerosas ni presentaban una calidad muy elevada ${ }^{65}$ Así la disminución del comercio acontecida a mediados del siglo xvir entre Filipinas y Nueva España pudo no estar tan influida por una contracción del comercio europeo y Atlántico, como defendió Pierre Chaunu, ${ }^{66}$ o por un reajuste en los sectores productivos novohispanos, ${ }^{67}$ sino por un descenso en la llegada de mercancías asiáticas hasta Manila, fruto de ciertos movimientos políticos y comerciales acontecidos en el continente asiático.

Aunque las alteraciones en la oferta de mercancías asiáticas en Acapulco no fueron los únicos cambios producidos en esta época, sino que estuvieron acompañados por la promulgación de una nueva real cédula en $1634,{ }^{68}$ que contó con una gran incidencia en el comercio americano y filipino. En ella, el monarca decretó de nuevo la prohibición del comercio entre Nueva España y Perú por el Pacífico, añadiéndole diversos edictos que impedían el tráfico asiático de mercancías con el puerto guatemalteco de Realejo, así como que el galeón se desplazara hasta el litoral de Huatulco. ${ }^{69}$ Estas normativas, unidas a la caída en el número y en la calidad de las mercancías llegadas hasta Nueva España, terminaron afectando el tráfico de productos asiáticos entre los dos grandes

65 Yuste López, “Allende el mar”, p. 243. LANG, El monopolio estatal del mercurio, pp. 101-105.

${ }^{66}$ Chaunu, Les Philippines et le Pacifique, pp. 230-232.

${ }^{67}$ Yuste López, El comercio de la Nueva España, pp. 33-34.

${ }_{68}$ Bonialian, El Pacífico hispanoamericano, p. 81.

${ }^{69}$ Yuste López, "El dinamismo rutinario”, pp. 212-213. 
virreinatos americanos por su vertiente pacífica, de modo que este tipo de contactos, aunque siguieron existiendo, ${ }^{70} \mathrm{se}$ hicieron menos visibles que en otras épocas.

De este modo, al descender el volumen de la carga de los galeones, el reducido número de mercancías asiáticas llegadas hasta la feria de Acapulco pudo ser absorbido sin dificultad por la demanda interna novohispana. De modo que los mercaderes limeños, conocedores de la escasez de mercancías y de la reducida cantidad de sedas y objetos de lujo que se podían cargar en Nueva España, pudieron decidir no arriesgar sus capitales en un comercio que, además de encontrarse prohibido, presentaba unos costes asociados importantes, sobre todo por la dificultad de la ruta. ${ }^{71}$

Por su parte, el estancamiento del trato por el Pacífico también acabó teniendo sus repercusiones en la otra orilla del océano, pues los vecinos de Manila vieron cómo el valor de sus mercancías disminuyó de manera sensible por el descenso de la demanda peruana y por el monopolio de la recepción de las mercancías por parte de los mexicanos. ${ }^{72}$

\section{LA MEJORA COMERCIAL DE FINALES DE LA DÉCADA}

DE 1670 Y PRINCIPIOS DE 1680

La década de 1660 fue una época muy dura para Filipinas; las tiranteces con los Zheng y diversos problemas de cariz

70 Sales Colín, “El movimiento portuario”, pp. 101-105.

71 Calderón, Historia económica de la Nueva España, p. 581.

72 "Y los caudales de los vecinos de que se componían las mercadurías que embiavan a Nueva España tenían grandes ganancias por estar avierto el trato de Pirú en aquel reyno.” AGI, Filipinas, 9, R. 1, N. 13. Carta del gobernador Diego Fajardo, 4 de agosto de 1650. 
interno produjeron que la entrada de mercancías chinas a Manila presentara uno de los índices más bajos desde la fundación de la ciudad, lastrando por completo a una economía filipina que llevaba varios años moviéndose en el filo de la navaja. Además, durante estos años, se produjo en Filipinas un espectacular auge del contrabando de productos insulíndicos e europeos, mercancías que no encontraban una salida comercial tan sencilla en América como las chinas, y que en muchos casos estaban destinadas únicamente al consumo interno de la población manileña.

En cambio, la década de 1670 fue mucho más benévola con la Gobernación, dejando entrever claros síntomas de recuperación económica que repercutieron sobre todo en el comercio. Así pues, durante estos años, los vecinos de Manila comenzaron a entretejer fuertes lazos mercantiles con territorios que anteriormente se habían escapado a su rango de influencia, como el subcontinente indio, región con la que aumentaron ampliamente los intercambios gracias a la llegada de armenios y portugueses a las costas de Luzón.

Mientras tanto, en China, las alteraciones volvieron a hacer acto de presencia. El proceso de conquista de las provincias meridionales emprendido por los Qing y las resistencia encontrada por parte de los leales Ming ante su avance habían permitido que una serie de generales al servicio de la nueva dinastía se asentaran en el sur del imperio, consolidando su poder en la región mientras se iban desvinculando progresivamente de la influencia de Beijing. Por esto, con el paso de los años, se conformaron unidades territoriales cuyos mandatarios actuaban como "príncipes" casi independientes. ${ }^{73}$

${ }^{73}$ Gernet, El mundo chino, pp. 420-421. 
De modo que, en 1670, Wu Sangui, controlaba las provincias de Guizhou, Hunan, Sichuan, Gansu, e incluso parte de Shaanxi, mientras que Geng Hingzhong extendía su dominio en Fujian y Sun Yanling hacía lo propio en Guangxi. El emperador Kangxi y su corte, conscientes de la creciente importancia de estos poderes autónomos, decidieron en 1673 iniciar su desarticulación, aprovechando para ello el vacío de poder existente en Cantón, acción que fue percibida por los antiguos generales como un importante agravio personal. ${ }^{74}$ Ante esta afrenta, Wu Sangui se levantó en armas contra el emperador, seguido por sus antiguos compañeros de armas, iniciándose un conflicto conocido como la Rebelión de los Tres Feudatarios.

La guerra abierta entre Beijing y los feudatarios no resultó nada sencilla para los ejércitos del emperador, quienes conocieron una serie de reveses en el campo de batalla que incluso llegaron a oídos de los vecinos de Manila. ${ }^{75}$ Esta tesitura fue aprovechada con presteza por un oportuno Zheng Jing, quien desplazó sus efectivos militares hasta el continente, con el objeto de recuperar su antiguo ascendente territorial sobre el litoral chino tras años recluidos en la isla de

74 Spence, “The K'ang-Hsi Reign”, p. 138.

75 "Y traen por nuevas, lleban en ttan buen estado los prinçipes de aquel ymperio el hechar de su dominio al tártaro, que de ttreze provinçias que ttiene la China le han quitado ya las siete. Y quedan continuando con ziertas esperanzas de que brevemente estará el ympero a la obediencia de legítimo dueño que lo es un hijo del desposehido, ya difunto. En el ynterín se goviernan con un governador en cada provinçia y el Sipuan de la Ysla Hermosa se halla en aquellas guerras con pretensión de mejorar de estado en aquel imperio.” AGI, Filipinas, 10, R. 1, N. 37. Carta de Manuel de León, 4 de junio de 1674. 
Taiwán, consiguiendo tomar rápidamente diversos enclaves de importancia en la costa de Fujian.

La guerra se cernía de nuevo sobre China, pero al contrario de lo acontecido durante las décadas anteriores, en esta ocasión el escenario bélico fue sumamente beneficioso para Manila y su actividad mercantil. Con el ejército Qing concentrado en el conflicto interno y con las tropas de Zheng Jing penetrando en la costa, el edicto que prohibía el comercio marítimo dejó de ser efectivo, y el trato directo entre Guandong y Fujian con Filipinas se reabrió. ${ }^{76}$ Este nuevo escenario permitió que la seda cantonesa, que durante los últimos años prácticamente había desaparecido de la bodega de los juncos chinos, retornara de nuevo a los almacenes de Cavite, aunque todavía en número muy reducido, ${ }^{77}$ sobre todo si lo comparamos con el elevado número de textiles de algodón llegados hasta Luzón durante esta época. ${ }^{78} \mathrm{~A}$ pesar de que el incremento de los intercambios entre China y Manila durante la Rebelión de los Tres Feudatarios fue claramente importante, el estado de guerra abierta vivida en el seno del imperio no permitió al comercio chino desarrollar todo su potencial, por lo cual, y a pesar de que los índices mercantiles registrados durante la rebelión superaron ampliamente a los recogidos durante las décadas anteriores, éstos ni siquiera se acercaron a los niveles de intercambios

\footnotetext{
76 WILls, "Maritime China”, p. 231.

77 AGI, Filipinas, 64, N. 1.

78 "Los mercaderes se lamentan oy mucho de estas regulaziones, diciendo que quando se hicieron venían género presioso y de grande valor y que oy se hallan grave mérito que biene son liensos bastos [que llaman elefantes], cosas de barros y otras de volumen.” AGI, Filipinas, 123, N. 2. Carta de Juan Baptista Medrizes, 30 de abril de 1678.
} 
alcanzados en los años previos a la desaparición de la dinastía Ming.

Por otra parte, mientras los disturbios se expandían en China, el trato manileño con la India comenzó un gradual aumento, sustentado en parte por la actividad de portugueses y armenios como intermediarios tanto de los comerciantes locales como de distintas compañías comerciales privilegiadas presentes en el subcontinente. $\mathrm{Al}$ mismo tiempo, los lazos entre los vecinos de Manila y los diferentes mercaderes asentados en la India se fueron haciendo cada vez más estrechos, llegando incluso a colaborar en varias empresas comerciales de manera conjunta. De este modo, grandes cantidades de textiles fabricados en la costa de Coromandel, como los elefantes y sarampunes, llegaron hasta las costas filipinas, a la vez que los Reales Almacenes de Manila se nutrían de considerables partidas de metales, salitre y anclas llegadas desde el subcontinete. ${ }^{79}$ Esta situación provocó un repunte de la llegada de textiles indios de algodón hasta la bahía de Manila, y permitió a las mercancías llegadas desde Surat, Coromandel y Bengala rivalizar, e incluso superar en determinados años al otrora hegemónico comercio chino.

Así, la confluencia de mercancías asiáticas en Manila generó un crecimiento de la oferta en la feria de Acapulco, situación que acabó repercutiendo en los circuitos internos novohispanos ${ }^{80}$ y en la vitalidad del eje comercial del Pacífico

79 Informe de los géneros y manufacturas compradas para los Reales Almacenes. AGI, Contaduría, 1240.

80 "Lo que viene de Philipinas en cada nao tiene estas distinziones, algunas parte no adeuda alcabala, porque o este presente o el dueño no la trae para vender a otra parte, pasa o a Huajaca y se reparte a otras provinzias y ciudades de este reyno particularmente a la Puebla de los Ángeles, pero 
americano, animando a mayor número de peruleros a aventurar sus capitales en los puertos del norte americano. De este modo, y como lo ha constatado Mariano Ardash Bonialian, se puede apreciar un auge en el número de naves que a partir de 1675 siguieron las rutas que unían el virreinato de Nueva España con el del Perú, ${ }^{81}$ hecho que coincide temporalmente con el incremento en la llegada de mercancías indias y chinas hasta Manila. Así pues, durante estos años, los mercaderes peruleros emprendieron un mayor número de viajes con rumbo a Acapulco y a la costa sur novohispana, donde solían intercambiar su vino, aceite, plata y cacao por productos locales y mercancías asiáticas.

Este repunte de la circulación en el Pacífico americano y la mayor participación de los mercaderes peruleros en el comercio de objetos asiáticos tuvo a su vez un efecto beneficioso para el trato en Filipinas, pues permitió que dos productos que contaban con una alta demanda en tierras asiáticas, como eran la plata y el cacao, llegaran en mayor número hasta Filipinas, favoreciendo así la capacidad de compra de los propios mercaderes manileños. Estos dos artículos eran de los pocos productos por los que los mercaderes chinos se sentían atraídos de cuantos podían ofrecerles los europeos y, por tanto, se convirtieron en piezas fundamentales para mantener abierto el trato con China. El chocolate tuvo buena aceptación en el sureste asiático, embarcándose importantes cantidades de cacao guatemalteco y peruano hasta Filipinas a pesar de que este vegetal ya se había adaptado satisfactoriamente a

todo esto junto es muy inferior porción a la principal que pasa a esta ciudad para venta." Carta de Juan Baptista Medrizes, 30 de abril de 1678. AGI, Filipinas, 123, N. 2.

${ }^{81}$ Bonialian, El Pacífico hispanoamericano, p. 450. 
las condiciones del archipiélago. ${ }^{82} \mathrm{~A}$ su vez, la demanda china de cacao provocó una alta cotización de este alimento en Luzón, de manera que los vecinos de Manila llegaron incluso a utilizar este alimento como si se tratara de una moneda cuando el numerario escaseaba, práctica que generó importantes desequilibrios económicos, así como diversos problemas sanitarios. ${ }^{83}$ Aunque sin duda alguna el producto estrella en los intercambios con China fue la plata, puesto que tanto la propia estructuración del sistema económico y fiscal chino como la insuficiente producción interna de este metal provocaron que este imperio no tuviera más alternativa que acceder a los mercados internacionales para conseguir cantidades suficientes del metal. ${ }^{84}$ De modo que, durante gran parte de los periodos Ming y Qing, China se vio obligada a atraer grandes cantidades de plata hacía el interior de sus fronteras, siendo los mercados filipino y japonés los principales encargados de ello. Esta continua absorción de metal argénteo por parte de China creó a su vez un elevado índice de demanda de este metal en otras zonas como la India, Siam o los diversos puertos controlados por los europeos en Asia para realizar determinadas transferencias. Es por ello que el crecimiento en el número de mercancías asiáticas llegadas a América y el consecuente incremento del transporte de plata hasta Filipinas

82 "Aora nuebamente an dado en sembrar cacao y se da tan bién como en América.” AHNE, Diversos-Colecciones, 31, N. 86. Relación escrita por Álvaro de Benavente, 6 de junio de 1677.

83 "La moneda de cacao es muy dañosa, pues andar entre leprosos y lázaros, siendo género que come a los muchachos y que los tenderos que se hallan con mucho cacao le hazen chocolate y lo venden." AGI, Filipinas, 23, R. 18, N. 60. Consulta del Cabildo secular de Manila, 10 de febrero de 1670.

${ }^{84}$ Flynn y Giraldez, "China and the Spanish Empire”, pp. 315-316. 
tuvo un efecto beneficioso tanto para la red comercial americana como para la asiática, retroalimentándose de manera conjunta y espoleándose entre sí por medio de los flujos de plata y los viajes de los galeones transpacíficos.

\section{EL DESPEGUE MERCANTIL DE FINALES DEL SIGLO XVII}

Tras el paulatino incremento acontecido en la década de 1670, durante los últimos compases del siglo XVII, el comercio filipino conoció un auge inusitado, aumentando el volumen del flujo mercantil asiático hasta Manila de una manera exponencial en solo unos pocos años.

Esta bonanza mercantil estuvo originada, principalmente, por las repercusiones que tuvo en China el final de la Rebelión de los Tres Feudatarios. Tras años de sangrientas guerras, las disputas mantenidas entre los Qing y sus antiguos generales, finalmente se acabó decantando del lado del emperador Kangxi, quien emprendió un incontestable avance hacia las provincias del sur. ${ }^{85}$ Por su parte, los feudatarios, incapaces de detener a las tropas imperiales, fueron cayendo uno tras otro durante los últimos años de la década de 1670 , aunque la revuelta no finalizó de manera oficial sino hasta

85 "De quatro años a esta parte, anda alborotada la China contra el tártaro que la domina. Y asín el año pasado de 76 fue tal el estrago que los tártaros hiçieron, y aun harán, que pienso ya no levantarán los chinos cabeza en mucho tiempo, cuentase los muertos por millares, sino por millones. Que no digo que me tengan por allá por fabuloso, que aquí estamos tan cerca y no çesa el trato, lo sabemos todo". Relación de fray Álvaro de Benavente, 6 de junio de 1677. AHN, Diversos-Colecciones, 31, N. 86. 
1681, cuando Wu Shinfan, hijo de Wu Shangui, se suicidó junto a la frontera de Tonquín. ${ }^{86}$

Con los principales focos de insubordinación bajo su control, Beijing consiguió vía libre para concentrarse en el frente contra los Zheng, emprendiendo una serie de acciones militares que obligaron a Zheng Jing a abandonar sus últimos reductos en la costa de Fujian en 1680. Derrotado y agotado, el talasócrata no tuvo más remedio que resguardarse de nuevo en la seguridad de la isla de Taiwán, en la que acabó muriendo tan solo un año más tarde. Con los Zheng fuera del continente, los Qing retomaron las medidas restrictivas al comercio costero, aunque en esta ocasión con mayor dureza y eficacia que en las décadas anteriores, menguando sensiblemente el tráfico marítimo chino en la región. Mientras tanto, en el interior de Taiwán, la repentina muerte de Zheng Jing dejó paso a una serie de intrigas palaciegas que no hicieron más que aumentar la división interna y menguar el ánimo entre la población. Ante esta tesitura, el emperador Qing decidió dar el golpe de gracia a un enemigo que ya se encontraba herido de muerte, emprendiendo en 1683 la conquista de Formosa sin que encontrara excesiva resistencia ante su avance. $^{87}$

Paradójicamente, la caída de Taiwán acabó resultando beneficiosa para los intereses mercantiles de Manila, puesto que a pesar de que durante años los hombres de negocios y mercaderes situados en la órbita de los Zheng supusieron casi el único método con el que contó Filipinas para acceder a mercancías chinas, la desaparición del régimen talasócrata

\footnotetext{
${ }^{86}$ Wakeman, The Great Enterprise, p. 1104.

${ }^{87}$ Yu-Ting, Taiwán. Historia, política e identidad, p. 46.
} 
permitió a los Qing revocar todos los decretos contrarios al comercio marítimo instaurados desde la década de 1650. Así pues, con los Zheng fuera de juego y con un nuevo marco legal que despenalizaba los intercambios marítimos, las ciudades del litoral recuperaron su proyección permitiendo al comercio chino recobrar la estabilidad que no disfrutaba desde hacía décadas. Como consecuencia de ello, el número de navíos llegados desde las provincias de Fujian y Guangdong hasta Luzón aumentó exponencial y súbitamente a partir de la anulación de los decretos, y en solo unos pocos años, el comercio chino recuperó un volumen semejante al conocido a principios de siglo. Entre 1683 y 1685, Manila pasó de recaudar 630 pesos por concepto de almojarifazgo de los navíos chinos, a alcanzar los 23223 pesos, cantidad que no se registraba desde $1637 .{ }^{88}$

Por su parte, el fin del bloqueo comercial chino también facilitó la entrada de mayor variedad de géneros en Filipinas, entre los que se podían encontrar zuecos, piedra de alumbre, té, almizcle, abanicos y diferentes tipos de porcelana, que se sumaban a los miles de tejidos de algodón que llegaban cada año a Manila. Por su parte, el fin de las hostilidades también repercutió en la recuperación de la producción china de tejidos de alta calidad, ${ }^{89}$ aumentando sensiblemente la llegada de rasos, satenes y seda sin manufacturar hasta Luzón. ${ }^{90}$

88 AGI, Filipinas, 24, R. 2, N. 14. AGI, Filipinas, 12, R. 1, N. 38.

89 Flynn y Giraldez, "Silk for Silver", p. 54.

90 El comerciante chino Yaqua portaba a bordo de su junco en 1686, 100 damascos labrados, 300 tafiras, 200 chaules, así como 4 picos de seda "quima”, dos picos de "seda floja” y 720 cates de seda cruda, entre muchas otras mercancías. AGI, Filipinas, 64, N. 1. Registro del junco de Yauqua, 18 de marzo de 1686. 
Sin embargo, el incremento del comercio chino no llegó solo, pues coincidió con la particular escalada de los intercambios que estaba teniendo lugar en estos momentos entre el archipiélago filipino y la India. De modo que durante estos años se produjo un paulatino incremento en la llegada a la ciudad manileña de comerciantes e intermediarios procedentes de Coromandel y Bengala cargados con distintos textiles de algodón, hierro y otros enseres. Pero este trato no fue únicamente unidireccional, pues los mercaderes manileños, conscientes de las oportunidades mercantiles de que disponía el subcontinente, comenzaron a acudir por sí mismos hasta estos enclaves, realizando tratos tanto con la población local como con los diferentes europeos presentes en la región. ${ }^{91}$ De manera que durante estos años, la afluencia de manufacturas provenientes de la India hasta Manila llegó a competir directamente con el renacido comercio chino, superándolo incluso en 1685 en cuanto al volumen de pesos pagados por concepto de almojarifazgo. ${ }^{92}$

Este auge sin precedentes del comercio manileño contó con una contrapartida, la legalidad vigente imponía una serie de restricciones al montante de mercancías que podían enviarse hasta Acapulco, las cuales se aplicaban directamente al tonelaje de los galeones. De modo que durante el siglo xvII,

91 "Hasta en India de Portugal, donde este declarante ha hecho algunos viages." Declaración de Francisco Enríquez de Losada, manileño de origen portugués, recogida en un memorial de la Orden de Santo Domingo, 24 de marzo de 1683. BHUV, Varios, 229, 11.

"Del cargo del capitán don Thomás Núñez de Loarca, vezino de la ciudad de Manila de vuelta del viaje que yço a la dicha Costa [de Coromandel].” AGI, Filipinas, 64, N. 1. Registro de la embarcación de Tomás Núñez de Loarca, $1^{\circ}$ de junio de 1681.

92 AGI, Filipinas, 12, R. 1, N. 38. 
se estipuló que la carga que podían albergar los navíos transpacíficos no podía superar en ningún caso los 250000 pesos de valoración, ${ }^{93}$ por lo que si atendemos a esta normativa, la oferta de productos asiáticos en Manila no tendría por qué repercutir en el número de mercancías que se introducían en el puerto de Acapulco, pues el coste de la carga de los galeones se encontraba delimitado de antemano. Aunque, realmente, el contenido de las reales cédulas relativas al volumen de la carga no siempre fue respetado, puesto que los vecinos de Manila encontraron diversos subterfugios que les permitieron introducir mayor número de mercancías de las autorizadas sin levantar demasiadas sospechas. Así pues, los galeones se cargaban en el puerto de Cavite sin contar con una regulación estricta ni un control riguroso, pues los capitanes generales realizaban la supervisión de las cargas sin hacer muchas preguntas relativas al contenido de las bodegas. ${ }^{94}$ Además, una vez que el galeón abandonaba el puerto y se adentraba en la provincia de Camarines, una serie de naves menores surtían a la embarcación transpacífica de nuevos fardos que se añadían a los ya cargados. Estratagema que quedó reflejada por la tripulación del galeón de Manila Santo Cristo de Burgos durante su viaje de 1692, quien narró cómo su navío realizó una parada en

93 Valdés LaKowsky, "La importancia de la plata novohispana”, p. 180. 94 "Dijo que vio cómo el piloto mayor y su acompañante reconoçieron la nao, vieron la carga y los rescrivieron a su contento sin poner de obise ni reparo alguno y no save este testigo que hiçiese protesta alguna." AGI, Filipinas, 26, R. 4, N. 18. Declaración de Sebastián Antonio García, pasajero del galeón Santo Cristo de Burgos, 2 de febrero de 1693. 
el puerto de Pola para tomar nuevas mercancías procedentes de una galeota que les vino al paso. ${ }^{95}$

La carga de nuevos fardos en los galeones antes de que éstos abandonaran las islas no resultó una práctica totalmente inocua ya que provocó toda una serie de problemas a las embarcaciones transpacíficas. ${ }^{96}$ Así pues, esta operación suponía una grave pérdida de tiempo, pues el lastre depositado en las bodegas debía ser reajustado, ${ }^{97}$ impidiendo que la embarcación saliera del embocadero de San Bernardino en las fechas más propicias para la navegación. ${ }^{98}$ Además, la introducción de nuevas mercancías provocaba la sobrecarga en las naves, originando diversos problemas en la navegación,

95 “Que desde que salió el dicho galeón del puertto de Cavitte, dio el general las órdenes nesesarias y procuró que no perdiese día de viage. Y quando estubo sotabentada en el puertto de Pola, se recivió la carga de fardos que llevó una galeotta que yva de comboy a cargo de Juan Gaspar, el cavo de ella." AGI, Filipinas, 26, R. 4, N. 18. Declaración de Ignacio Vázquez, artillero del galeón Santo Cristo de Burgos, 9 de febrero de 1693. 96 "Como estaba sobrecargado respecto de tener la manga devajo del agua, faltándole aún todavía que meter alguna aguada y bastimentos, y que para conseguir y asegurar el viaje era preziso dijarle alguna carga." AGI, Filipinas, 14, R. 3, N. 40.Carta de Fausto Cruzat y Góngora, 12 de julio de 1691.

97 "Porque los tiempos siempre fueron escasos, como en la ocasión referida, que escaseó el vientto, fue presiso coger el puertto de Pola, donde se bolvió a remover la carga de dicho galeón por parezer no habían cargodo, esto es la tinajerá que yva a popa y otras menudenias, que todo se ecchó en proa para governarse mejor la nao.” AGI, Filipinas, 26, R. 4, N. 18. Declaración de Andrés Medina, maestre del galeón Santo Cristo de Burgos, 10 de febrero de 1693.

98 "Pero oyó desir este testigo a algunas personas y a Juan de Molina, alguazil de agua, que podían con aquel vientto aber llegao a Ticao la dicha nao, sino se ubiera atracado a la tierra de Marínduque." AGI, Filipinas, 26, R. 4, N. 18. Declaración de Andrés Medina, maestre del galeón Santo Cristo de Burgos, 10 de febrero de 1693. 
que en muchas ocasiones dificultaban la salida de los galeones de las islas u obstaculizaban su llegada a Acapulco. ${ }^{99}$ Por lo que no resulta extraño que la llegada masiva de mercancías chinas e indias hasta Manila viniera acompañada por un sensible aumento en el número de accidentes sufridos por los galeones, que contrasta con la regularidad y seguridad mostrada por esta ruta durante las décadas anteriores. Así pues, a finales de la década de 1680, el "dinamismo rutinario" 100 que había presidido los viajes entre Manila y Acapulco desde 1640, dejó paso a un elevado número de incidentes, a pesar de que el tamaño y la capacidad de los galeones aumentó considerablemente durante estos años con el objeto de absorber el mayor número posible de mercancías. De este modo no se pudo enviar nave alguna ni a América ni a Guam durante 1686, mientras que en 1687, el Santo Niño, uno de los galeones más grandes construidos hasta la fecha en Luzón, quedó varado en Solsogón. ${ }^{101}$ A su vez, en 1692 el Santo Cristo de Burgos no consiguió salir del embocadero, incendiándose un año más tarde en alta mar, mientras que en 1694 el San José quedó encallado en Mariveles, siguiendo un destino similar al del Nuestra Señora de Guía. De manera que se puede apreciar un paralelismo entre el incremento en la llegada de mercancías a Manila, el aumento en el tamaño de los galeones y la ruptura de la estabilidad y seguridad que se

\footnotetext{
99 "Oyó dezir este testigo que la veuza de cavezear la nao mucho, unos decían que era porque escaseava el viento, otros deçían porque yva cargada a proa y otros decía qu caveseava por cauza de estar cargada a popa." AGI, Filipinas, 26, R. 4, N. 18. Declaración de Gabriel de Aguirre, artillero del galeón Santo Cristo de Burgos, 8 de febrero de 1693.

100 Yuste López, "El dinamismo rutinario", p. 204.

101 Varela, "Microhistoria de un galeón”, pp. 237-239.
} 
había establecido en la ruta entre Luzón y Acapulco. No es de extrañar que en 1702, la corona intentara adaptar las normativas a las nuevas circunstancias del comercio transpacífico, aumentando hasta los 600000 pesos el coste de las mercancías que se podían transportar rumbo a América en las bodegas de los galeones de Manila, ${ }^{102}$ aunque esta medida tampoco consiguió poner fin a la carga de fardos fuera de registro. ${ }^{103}$

A su vez, la bonanza e incremento del volumen de negocios de la carrera de Acapulco también atrajeron el interés de los grandes comerciantes mexicanos por la intervención directa sobre el propio territorio filipino, pues al prescindir de intermediarios, los precios de las mercancías se reducían y las ganancias se multiplicaban. Aunque esta práctica había sido prohibida en 1593, al excluirse a todos los no residentes en Manila del trato con Asia, continuó desarrollándose de manera solapada por medio de toda una serie de subterfugios. ${ }^{104}$ Así pues, muchos de los europeos y americanos presentes en Filipinas eran en realidad agentes, familiares o socios de importantes hombres de negocios mexicanos, que recibían grandes cantidades de numerario procedente de Nueva España para destinarlo al comercio asiático.

Estas estrategias, a pesar de haberse mantenido durante todo el siglo, se hicieron cada vez más evidentes a partir de la década de 1670, coincidiendo con la apertura de los mercados chino e indio y con el incremento de los intercambios. De manera que no es de extrañar que en 1677, 1678 y 1686, se decretaran una serie de reales cédulas en las que se dejaba

\footnotetext{
102 Valdés Lakowsky, “La importancia de la plata novohispana”, p. 180.

103 Baudot Monroy, “Cubrir la nueva ruta del galeón”, pp. 345-346.

104 Yuste López, “De la libre contratación”, pp. 85-106.
} 
entrever la reiterada contravención de estas disposiciones, haciendo alusión a diversos "embargos" de plata y bienes en Acapulco y Manila a comerciantes novohispanos pertenecientes al Consulado de la Ciudad de México, mientras que en 1683 , los manileños se quejaron ante el rey de que los novohispanos habían enviado 400000 pesos a Filipinas para la adquisición de mercancías.

Por su parte, el incremento del volumen del comercio también provocó que a finales del siglo XviI accedieran a la presidencia de la Audiencia filipina una serie de personajes, que por primera vez en todo el siglo no habían sido designados por sus méritos, sino por la compra de su cargo, y que además contaban con fuertes lazos con el comercio y con diversos hombres de negocios novohispanos. De modo que el gobernador Gabriel de Curucelaegui (1684-1689) había ocupado antes de llegar a Manila el puesto de almirante de galeones de la flota atlántica, mientras que Fausto Cruzat y Góngora (1690-1701) se encontraba inmerso dentro de la red clientelar de los Tagle, con quien mantenía una estrecha relación desde la década de 1670 , por lo que no es de extrañar que la influencia de los novohispanos en el tránsito transpacífico se hiciera más evidente durante sus mandatos. Así pues, en 1686, el virrey Conde de Galve autorizó que dos navíos se embarcaran en dirección a Luzón con comerciantes mexicanos y peruanos, llevando consigo tanto importantes cantidades de plata como diversos modelos de tejidos muy apreciados en las Indias para que éstos fueran copiados por los artesanos chinos. ${ }^{105}$ El envío de mercaderes americanos a tierras Filipinas no cesó aquí, pues en 1691,

105 Bonialian, El Pacífico hispanoamericano, p. 178. 
el virrey Conde de Galve cambió toda la plana mayor del galeón Santo Cristo de Burgos por novohispanos, colocando al frente de la nave, como capitán general, al vecino de México, Pedro Íñiguez Bayo. ${ }^{106}$ Este nombramiento supuso una flagrante violación de la legalidad vigente referente a este tipo de viajes, pues solamente los gobernadores de Filipinas tenían potestad para elegir a los capitanes de los galeones. ${ }^{107}$ Pero a pesar de ello, y de existir diversas sentencias previas referentes al mismo asunto, ${ }^{108}$ el presidente de la Audiencia asiática no solo no condenó este nombramiento, sino que ratificó a Pedro Íñiguez de Bayo en su cargo, ${ }^{109}$ por lo que esta reordenación de la escala de mando del galeón no se trató de un mero hecho anecdótico, sino que permite

106 "Y haviendo llegado al puerto de Acapulco de dicho reyno, vuestro virrey conde de Galve, en contrabenzión de lo dispuesto por Vuestra Magesta, despojó de dicha plaza de general al dicho don Françisco de Arcocha, poniendo en su lugar para el tornabiaje del galeón al capitán de cavallos don Bernardo Yñíguez de Bayo, residente en la ciudad de México. [...] Y no sólo hizo dicho virrey mutazión en la plaza de general, sino también en las de sargento mayor, mastre y contramaestre del galeón, cosa que se a estrañado notablemente así en toda la Nueva España como en estas yslas". AGI, Filipinas, 26, R. 4, N. 10. Carta de Fausto Cruzat y Góngora, 12 de diciembre de 1691.

107 AGI, Filipinas, 26, R. 4, N. 18. Real Cédula de 22 de abril de 1673.

108 Herrera Reviriego, "Motín a bordo".

109 "Para cuyo efecto se está aprestando en el puerto y rivera de Cavite el galeón capitana sancto christo de Burgos y conviene nombrar persona que sirva la plaza de general de él que sea de toda satisfaçión y confianza y de las partes y calidades que se requiere. Y porque éstas concurren en la vos, el capitán de cavallos, corasas y general don Bernardo Yñíguez de Bayo, theniendo considerazión a los servizios que me aveis tenido, con el crédito y aprovasión que es notorio". AGI, Filipinas, 26, R. 4, N. 18. Nombramiento de Bernardo Íñiguez de Bayo como capitán general del galeón Santo Cristo de Burgos en 1692. 
entrever cómo la intervención novohispana en el comercio filipino tuvo diversas intensidades durante la segunda mitad del siglo xvir. Pues en contra de lo acontecido en 1663, cuando el virrey Conde de Baños nombró a un nuevo capitán general para el galeón San José con el objetivo de descubrir una ruta hacia las islas Salomón, ${ }^{110}$ durante 1691, ni la tripulación ni las autoridades manileñas se opusieron frontalmente a la designación del virrey; es más, el propio gobernador de Filipinas, Fausto Cruzat y Góngora, ratificó este nombramiento un año más tarde, encomendando a Íñiguez Bayo el viaje anual a Acapulco. ${ }^{111}$ La práctica de nombrar a comerciantes mexicanos como capitanes generales de los galeones no cesó aquí, puesto que durante los años 1700 y 1701 ocuparon este mismo cargo los futuros marqueses de Altamira y Sierra Nevada, Luis Sánchez de Tagle y Domingo Ruiz de Tagle, quienes mantenían fuertes lazos con el gobernador filipino desde sus años de estancia en Cádiz. De todos modos, no solo los mercaderes mexicanos aumentaron su intervención directa en Filipinas durante estos años, sino que también diversos peruanos decidieron cruzar el

110 Herrera Reviriego, "Motín a bordo".

111 "Para cuyo efecto se está aprestando en el puerto y rivera de Cavite el galeón capitana sancto christo de Burgos y conviene nombrar persona que sirva la plaza de general de él que sea de toda satisfaçión y confianza y de las partes y calidades que se requiere. Y porque éstas concurren en la vos, el capitán de cavallos, corasas y general don Bernardo Yñíguez de Bayo, theniendo considerazión a los servizios que me aveis tenido, con el crédito y aprovasión que es notorio". AGI, Filipinas, 26, R. 4, N. 18. Nombramiento de Bernardo Íñiguez de Bayo como capitán general del galeón Santo Cristo de Burgos en 1692. 
Pacífico a bordo de los galeones para adquirir mercancías asiáticas a bajos precios. ${ }^{112}$

Por otra parte, el rápido incremento en la llegada de productos hasta Luzón, no solo conllevó grandes cambios en los viajes de los galeones de Manila, sino que también influyó de manera importante en el comercio americano. Así pues, el incremento de la oferta de productos chinos e indios en Nueva España fue tan súbito e importante, que los propios comerciantes de la ciudad de México tuvieron que pedir licencias extraordinarias para que se les permitiera vender estos géneros en las calles, plazas y tiendas menores, pues no cabían dentro de sus almacenes. ${ }^{113}$ Mientras, en el Pacífico, el aumento de la oferta produjo la revitalización de la ruta mercantil ilícita, produciéndose un auge tanto en la llegada de navíos peruleros hasta Acapulco ${ }^{114}$ como en el envío de navíos de mercaderes mexicanos hasta El Callao. ${ }^{115}$ De manera que incluso los propios galeones de Manila pudieron promover activamente esta red semiinformal, trasladándose a parajes tan meridionales como Soconusco ${ }^{116} \mathrm{o}$ entrando en contacto con navíos peruleros antes de alcanzar el meridional puerto de Navidad. ${ }^{117}$ De todos modos, el eje mercantil

\footnotetext{
112 Bonialian, El Pacífico hispanoamericano, p. 290.

113 Bonialian, "Las aguas olvidadas", pp. 1016-1017.

114 Bonialian, El Pacífico hispanoamericano, pp. 274-275.

115 Bonialian, "Las aguas olvidadas", pp. 1031-1033.

116 "Visto gente de a cavallo en la playa, que les dixeron que si era el navío de Philipinas estava mui propasado del puerto de Acapulco y que aquel paraje era jurisdicción y govierno de Soconusco, que está antes del de Guatemala”. AGI, Filipinas, 123, N. 2. Testimonio de Juan de Aguilar, presbítero del galeón Nuestra Señora del Pilar de Zaragoza, 15 de enero de 1700. 117 "Y al día siguiente que se asercaron reconocieron ser un navío perulero que salía en busca de un cosario, que dixeron que andava en la
} 
del Pacífico no solo se nutrió de mercancías asiáticas, pues los peruleros trasladados hasta Acapulco también adquirieron en Nueva España tanto productos europeos traídos por las flotas como géneros de procedencia novohispana. El auge del tráfico por la Mar del Sur también acabó animando las otras vías mercantiles indianas, incentivando la producción interna americana, así como el intercambio entre virreinatos. Se puede apreciar cómo paralelamente al incremento de la intensidad del comercio en el eje del Pacífico, las flotas mexicanas comenzaron a ser más periódicas y las mercancías cargadas en ellas mucho más numerosas, ${ }^{118}$ pasando, según los cálculos de J. Everaert, de los 10000000 de pesos trasladados hasta la península ibérica en 1685, a los 30000000 en $1697 .{ }^{119}$ Mientras, en Panamá los temores expresados por Francisco Valverde de Mercado en 1606 se hicieron palpables, ${ }^{120}$ pues la reexportación ilegal de géneros asiáticos y mercancías europeas y castellanas por el Pacífico hizo que la carrera de

costa. Del qual rezivieron seis petates de Viscocho, porque yban faltto de él, y siguiedo cada uno su derrota." A GI, Filipinas, 123, N. 2. Testimonio de Pascual Fernández Cordero, contramaestre del galeón Nuestra Señora del Pilar de Zaragoza, 19 de enero de 1700.

118 Bonialian, "México, epicentro semiinformal”, p. 20.

119 Citado en Oliva Melgar, "La metrópoli sin territorio", p. 26.

120 "Ni oy conozco este reino, porque beó los V.S del pobres llenos de travajos y neçesidades muchas, casas despobladas y las demás tan flacas en el tratrato de ellas que se hecha muy bien de ver que va padeçiendo ruina. Y si Vuestra Magestad, con su poderosa mano no lo remedia estorvando la contrataçión de la China con el Pirú por la Nueva España y la propia contratación con los demás reinos de estas Yndias, como lo tengo ferito a Vuestra Magestad desde México. [...] Por lo que a mí me tocase aseguro a Vuestra Magestad que sirviéndose de mandar que se queme la rropa de China, aunque sean cosas caseras.” AGI, Panamá, 15, R. 7, N. 58. Carta de Francisco Valverde de Mercado, 30 de enero de 1606. 
Portobelo entrara en un profundo declive, reduciéndose la frecuencia de sus flotas y presentando numerosas dificultades para situar sus productos en un mercado cada vez más competitivo. $^{121}$

Todo este flujo mercantil provocó a su vez una salida masiva de plata americana hacia Europa y Asia, fluyendo especialmente en dirección a China, que se encontraba más necesitada que nunca de las reservas argénteas americanas tras que en 1680 el shogun prohibiera la venta de plata japonesa al exterior. ${ }^{122}$ De modo que para alcanzar las cantidades de metal suficientes para poder saciar la demanda producida por el nuevo ritmo de intercambios entre Asia y América, el virreinato novohispano se vio obligado a aumentar la extracción de sus minas, tarea para la que necesitaba cantidades de mercurio que no se encontraban disponibles en su propio territorio. Así, a finales del siglo xviI, Nueva España no tuvo más remedio que recurrir a la importación de grandes cantidades de azogue proveniente de sus diferentes vínculos comerciales. Entre 1699 y 1713, desde la península ibérica se enviaron cuatro pares de navíos cargados con este elemento, mientras que los barcos provenientes del virreinato del Perú transportaron consigo importantes cantidades de mercurio en sus viajes hasta las costas occidentales de Guatemala y México. ${ }^{123}$ De igual modo, la afluencia de azogue no consiguió colmar la demanda, y durante la última década del siglo xvir, Nueva España no tuvo más remedio que tantear nuevos mercados donde adquirir este producto, siendo

\footnotetext{
121 Bonialian, El Pacífico hispanoamericano, pp. 260, 274-275.

122 LeE, "Trade and Economy", pp. 8-9.

${ }^{123}$ Bonialian, El Pacífico hispanoamericano, pp. 261, 272-275.
} 
el chino uno de los elegidos para ello. ${ }^{124}$ En 1692, el virrey Conde de Galve envió una elevada suma de pesos a Manila para que su gobernador adquiriera mercurio de procedencia china y analizara su calidad, precio y posibilidades comerciales, a pesar de que ya se contaba con informes positivos de inicios de siglo. ${ }^{125}$ Tras examinar la calidad de este producto, el Consejo de Indias quedó sumamente satisfecho, pues resultó ser mucho más barato que el azogue peruano que se adquiría vía Acapulco, así como de una calidad semejante al que se extraía de las minas ibéricas de Almadén. ${ }^{126}$ Mientras, las autoridades novohispanas y los comerciantes de una y otra parte del Pacífico también se mostraron complacidos, pues el mercurio chino tributaba por debajo del de Almadén y permitía crear flujos de plata no controlados por la corona con destino a Asia. ${ }^{127}$ Durante los años siguientes, el gobernador Fausto Cruzat y Góngora

${ }^{124}$ Del Valle Pavón, “Bases del poder”, p. 583.

125 AGI, México, 27, N. 52. Carta de Luis de Velasco de 23 de junio de 1608.

126 "Se deve liberar despacho para que este governador y los subsiguientes en aquel govierno procuren poner en corriente este comercio y negoziación, respecto de la gran nezesidad que se padeze de este metal en la Nueva España y ser el precio más acomodado que los de Perú, que pasan de los 100 pesos por quintal puestos en Acapulco. Siendo así que por la experiencia que se hizo en la Nueva España, del quintal y medio, antesedetemente se había remitido este governador, equivalía la vondad a los de la mina del Almadén”. AGI, Filipinas, 15, R. 1, N. 43. Respuesta del Consejo de Indias, 29 de mayo de 1696.

127 "Con que no solo no resulta el útil que se de a entender del asogue de la China, sino al contrario, gravisimos perjuicios a mi real herario y a la causa pública, así por la extracción de la platta de su importe como por lo que con semejante introducción se aumentarían los fraudes que en aquellas provinçias y en todas las indias se experimentan en la recaudación de mis reales quintos.” AGI, Filipinas, 129, N. 150. Real cédula de 23 de junio de 1709. 
compró importantes partidas de este material en Cantón y en Macao para enviarlas a bordo de los galeones de Manila rumbo a Nueva España, ${ }^{128}$ siendo estos intercambios muy beneficiosos para el mercado asiático, pues los hispánicos pagaban con plata el azogue, que en un futuro se emplearía para extraer más plata, destinada a ser intercambiada a su vez por mercancías chinas. Este caso concreto nos permite apreciar cuán estrecha fue la interconexión entre las redes mercantiles asiáticas y americanas, y las distintas direcciones que tomaron los productos que se transportaron en estas vías comunicativas y comerciales.

Otra muestra de la influencia recíproca entre las redes americana y asiática y su polidireccionalidad la encontramos en el hecho de que el incremento en la llegada de mercancías asiáticas hasta Manila produjo, indirectamente, un aumento en la presencia de géneros procedentes de América y Europa en esta ciudad filipina. Este hecho no resultaba novedoso, pues desde la conquista hispánica de Filipinas, la Gobernación se vio obligada a recurrir a los mercados exteriores, ya fuera mediante la vía del galeón o de los comerciantes portugueses, para adquirir ciertos productos que no podían encontrarse de forma natural en las islas, tales como el vino de vid, el aceite de oliva o diferentes artilugios metálicos. ${ }^{129}$ Artículos a los que se les sumaba la demanda de ciertos objetos de prestigio y de identificación de clase social, tales como los sombreros valones o los paños castellanos y mexicanos, por parte de los mercaderes más adinerados de

128 " 59 quintales y 13 libras y media de dicho azogue que se compraron en Macán, reyno de Cantón, cuyo valor ymportó 3.748 pesos.” AGI, Filipinas, 17, R. 1, N. 25. Carta de Fausto Cruzat y Góngora, 3 de junio de 1698. ${ }^{129}$ Alva Rodríguez, Vida municipal en Manila, p. 38. 
Manila. ${ }^{130}$ Aunque la demanda de estos productos desde el archipiélago filipino fue continuada, la caída demográfica de la población de origen europeoamericano a mediados del siglo XVII ${ }^{131}$ redujo considerablemente la solicitud de estos géneros. De modo que, a consecuencia del incremento demográfico que sufrió la ciudad de Manila con la mejora de sus condiciones económicas acontecidas a finales de siglo, la demanda de estos productos se multiplicó, quedando evidencia de ello en las grandes cantidades de vino, sombreros, fieltros y cerradas de Castilla que se cargaron, formando parte del situado ${ }^{132}$, en el galeón de Manila San Telmo en $1678 .{ }^{133}$

\section{CONCLUSIONES}

Como hemos podido comprobar, durante la segunda mitad del siglo xvir, Asia, América y Europa se encontraron fuertemente interconectadas entre sí por vínculos mercantiles, comunicativos y económicos, por lo que el advenimiento de cambios significativos en alguna de estas regiones acabó produciendo profundas repercusiones en el resto. De modo que un hecho tan alejado del día a día americano como fue la caída de la dinastía Ming o la llegada de unos pocos mercaderes

130 Sales Colín, “Los cargazones del galeón”, p. 639.

131 "Por no llegar el número de vezinos españoles [de Manila] a veinte y cinco". AGI, Filipinas, 9, R. 3, N. 48. Carta de Sabiniano Manrique de Lara, 8 de octubre de 1666.

132 Desgraciadamente no contamos con el informe de las mercancías que los comerciantes privados cargaron en las bodegas de este galeón, aunque dentro del situado de dicho navío se registraron diferentes productos con un claro interés comercial, que poco o nada tenía que ver con las necesidades de los Reales Almacenes de Manila.

133 AGI, Filipinas, 11, R. 1, N. 4. 
armenios hasta Luzón, acabó teniendo una fuerte repercusión tanto para el sistema de flotas como para el comercio semiinformal del Pacífico. Por ello, se pueden llegar a trazar paralelismos entre los flujos comerciales asiáticos y americanos, así como a considerar la fuerte intercomunicación y vinculación mantenida entre ambas partes.

A su vez, una reflexión detenida de la conexión entre las distintas redes permite apreciar la elevada complejidad del mercado del Pacífico, que lejos de ser un mero espejo del tráfico del Atlántico, como defendió Pierre Chaunu, contó con dinámicas propias e individuales en las que intervinieron una enorme multiplicidad de factores. De modo que el comercio en el Pacífico no se mantuvo subordinado al del Atlántico, sino que ambos mercados se encontraron estrechamente interconectados, influenciándose, vertebrándose y espoleándose de manera mutua, por lo que no resulta extraño que uno y otro espacio mercantil se comportaran de manera similar o que reprodujeran los mismos periodos de ascenso y de caída.

A su vez, el mantenimiento del flujo comercial entre Filipinas, Nueva España y el virreinato de Perú, a pesar de las sucesivas trabas y restricciones impuestas desde Madrid, permite apreciar la multiplicidad de actores que intervenían en la estructuración y vertebración de la Monarquía Hispánica, y cómo algunos de ellos incluso se encontraban fuera de sus propias fronteras.

\section{SIGLAS Y REFERENCIAS}

AGI Archivo General de Indias, Sevilla, España.

AHN Archivo Histórico Nacional de España, España.

APSR Archivo de la Provincia del Santo Rosario, Manila, Filipinas. 
BHUV Biblioteca Histórica de la Universidad de Valencia, España.

VOC Vereenigde Oost-Indishe Compagnie.

Alonso Álvarez, Luis

"E la nave va. Economía, fiscalidad e inflación en las regulaciones de la carrera de la Mar del Sur, 1565-1604”, en BERNAbéu Albert y Martínez Shaw, 2013, pp. 25-84.

Alva Rodríguez, Inmaculada

Vida municipal en Manila (siglos XVI-XVII), Córdoba, Universidad de Córdoba, 1997.

"Ciudad y comercio en el siglo xviII. El galeón de Manila en el desarrollo de la vida municipal”, en Bernabéu Albert y Martínez Shaw, 2013, pp. 180-181.

Andaya, Leonar Y.

"The Informal Portuguese Empire and the Topasses in the Solor Archipelago and Timor in the Seventeenth and Eighteenth Centuries", en Journal of Southeast Asian Studies, 41:3 (2010), pp. 391-420.

Andrade, Tonio

“The Company's Chinese Pirates: How the Dutch East India Company Tried to Lead a Coalition of Pirates to War against China, 1621-1662", en Journal of World History, 15:4 (2004), pp. 295-321.

"A Chinese Farmer, Two African Boys, and a Warlord: Toward a Global Microhistory", en Journal of World History, 21:4 (2010), pp. 573-591.

Aslanian, Sebouh David

From the Indian Ocean to the Mediterranean. The Global Trade Networks of Armenian Merchants from New Julfa, Berkeley y Los Ángeles, University of California Press, 2011. 
Baena Zapatero, Alberto

"Un ejemplo de mundialización: el movimiento de biombos desde el Pacífico hasta el Atlántico (siglos XviI-XviıI)", en Anuario de Estudios Hispano-Americanos, 69:1 (2012), pp. 31-62.

Ballantyne, Tony

"Putting the nation in its place? World history and C. A. Bayly's The Birth of the Modern World", en Curthoys y LAKE, 2005, pp. 23-44.

BArrón Soto, María Cristina

Urdaneta novobispano: la inserción del mundo hispano en Asia, México, Universidad Iberoamericana, 2012.

Barros Guimerans, Carlos (coord.)

Historia a debate: actas del Congreso Internacional "A historia a debate", celebrado el 7-11 de julio de 1993 en Santiago de Compostela, Santiago de Compostela, Historia a Debate, 1995.

Bascara, Cornelio y Marcelino A. Foronda Jr.

Manila, Madrid, Mapfre, 1992.

Baudot Monroy, María

"Cubrir la nueva ruta del galeón: la conquista de las islas Batanes”, en Bernabéu Albert y Martínez Shaw, 2013, pp. 341-379.

Bernabéu Albert, Salvador

La Nao de China, 1565-1815: navegación, comercio e intercambios culturales, Sevilla, Universidad de Sevilla, 2014.

Bernabéu Albert, Salvador y Carlos Martínez Shaw

Un océano de seda y plata: el universo económico del Galeón de Manila, Sevilla, Consejo Superior de Investigaciones Científicas, 2013. 
Bernal, Antonio Miguel

"La 'carrera del Pacífico': Filipinas en el sistema colonial de la carrera de Indias", en CABrero, 2004, pp. 485-545.

Bertrand, Romain

"Rencontres impériales. L'histoire connectée et les relations euro-asiatiques", en Revue d'bistoire moderne et contemporaine, 54:4 bis (2007), pp. 69-89.

L'Histoire à parts égales: Recits d'une recontre, Orient-Occident (xvie-xviie siècles), París, Seuil, 2011.

Blumentritt, Fernando

Filipinas. Ataques de los holandeses en los siglos XVI, XVII y XVIII, Madrid, Imprenta de Fortanet, 1882.

Bonialian Assadourian, Mariano Ardash

"México, epicentro semiinformal del comercio hispanoamericano (1680-1740)", en América Latina en la historia económica, 35 (2011), pp. 6-28.

El Pacífico hispanoamericano: política y comercio asiático en el Imperio Español, 1680-1784, México, El Colegio de México, 2012.

"Las aguas olvidadas de la mar del sur. Comerciantes novohispanos y sus reexportaciones de mercancías extranjeras hacia Perú (1680-1740)", en Historia Mexicana, LXI:4 (244)(abr.jun. 2012), pp. 995-1047.

"La contratación de la China por América colonial a principios del siglo xvir. La mirada de Francisco Valverde de Mercado, gobernador de Panamá”, en Boletín del Instituto de Historia Argentina y Americana, XL:3 (2015), pp. 11-41.

Brasó Broggi, Carles (coord.)

Los orígenes de la globalización: el Galeón de Manila, Shangai, Biblioteca Miguel de Cervantes de Shangai, 2013. 
Borao Mateo, José Eugenio

Spaniards in Taiwán, Taipei, SMC Publishing, 2002.

Buschmann, Rainer F.

Oceans in World History, Nueva York, McGraw-Hill, 2007.

Cabrero, Leoncio (ed.)

España y el Pacífico: Legazpi, Madrid, AM3, 2004.

Calderón, Francisco

Historia económica de la Nueva España en tiempo de los Austrias, México, Fondo de Cultura Económica, 1995.

Cañizares esguerra, Jorge y Erik R. Seeman (eds.)

The Atlantic in Global History, 1500-2000, Upper Sandle River, New Jersey, Prentice Hall, 2007.

Chaunu, Pierre

Les Philippines et le Pacifique des Ibériques (XVI, XVII, XVIII sièclaes), París, sevpen, 1960.

Coello de la Rosa, Alexandre, Javier Burrieza y Doris Moreno Jesuitas e imperios de ultramar. Siglos XVI-XX, Madrid, Sílex, 2012.

Curthoys, Ann y Marilyn Lake (coord.)

Connected Worlds. History in Transnational Perspective, Canberra, The Australian National University Press, 2005.

Dennerline, Jerry

“The Shun-Chih Reign”, en Twitchett y Fairbank, 2002, pp. 73-118.

Elliott, John H.

“Comparative History”, en BArros, 1995, pp. 9-20. 
FANG, Chen Chen

El comercio entre los sangleyes y Luzón (1657-1687), análisis, traducción y anotación de las fuentes [華人與呂宋貿易(16571687): 史料分析與譯註], Hsinchu, National Tsing Hua University Press, 2012.

Flynn, Dennis y Arturo Giraldez

"Born with a Silver Spoon: The Origins of World Trade in 1571”, en Journal of World History, 6 (1995), pp. 201-221.

"China and the Spanish Empire", en Revista de Historia Económica, 14:2 (1996), pp. 309-338.

"Silk for Silver: Manila-Macao trade in the 17th Century", en Philippine Studies, 44:1 (1996), pp. 52-68.

García-Abásolo, Antonio

"Los chinos y el modelo colonial español en Filipinas", en Cuadernos de Historia Moderna. Añejos, 10 (2010), pp. 233-242.

Gernet, Jacques

El mundo chino, Barcelona, Crítica, 1991.

Geyer, Michael y Charles Bright

"World History in a Global Age", en The American Historical Review, 100:4 (1995), pp. 1034-1060.

GiL, Juan

Los chinos en Manila. Siglos XVI y XVII, Lisboa, Fundação para Ciência e Tecnologia, 2011.

Gilbert, Erik y Jonathan T. ReYnolds

Trading Tastes: Commodity and Cultural Exchanges to 1750, Nueva York, Prentice Hall, 2005.

Gould, Eliga H.

"Entangled Histories, Entangled Worlds: The English-Speaking Atlantic as Spanish Periphery", en The American Historical Review, 112:3 (2007), pp. 764-786. 
Gruzinski, Serge

"Les mondes mêlés de la Monarchie catholique et autres 'connected histories', en Annales. Histoire, Sciences Sociales, 56:1 (2001), pp. 85-117.

Gunn, Geoffrey C.

First Globalization. The Eurasian Exchange, 1500-1800, Lanham, Rowman and Litterfield, 2003.

History Without Borders. The Making of an Asian World Region, 1000-1800, Hong Kong, Hong Kong University Press, 2011.

Halikowski-Smith, Stefan

"Globalisation Before Globalisation: the Case of the Portuguese World Empire, 1415-1808”, en Jalagin, Tavera y DilLEY, 2011, pp. 25-46.

HAN, Qi

"La influencia del Galeón de Manila sobre la dinastía Ming", en Brasó Broggi, 2013, pp. 67-104.

Herrera Reviriego, José Miguel

"Motín a bordo: conflicto y choque de jurisdicciones en el Galeón de Manila San José”, en Bernabéu Albert, 2014, pp. 65-90.

Jalagin, Seija, Susanna Tavera y Andrew Dilley (eds.)

World and Global History. Research and Teaching, Pisa, Pisa University Press, 2011.

LANG, Mervin

El monopolio estatal del mercurio en el México colonial (15501570), México, Fondo de Cultura Económica, 1977.

LEE, John

"Trade and Economy in Preindustrial East Asia, c.1500c. 1800: East Asia in the Age of Global Integration”, en The Journal of Asian Studies, 58:1 (1999), pp. 2-26. 
LOCKARD, Craig

“'The Sea Common to All': Maritime Frontiers, Port Cities and Chinese Traders in the Southeast Asian Age of Commerce, ca. 1400-1750", en Journal of World History, 21:2 (2010), pp. 219-247.

Luque Talaván, Miguel y Marta María Manchado López (coords.)

Un océano de intercambios: Hispanoasia (1521-1898). Homenaje al profesor Leoncio Cabrero Fernández, Madrid, Ministerio de Asuntos Exteriores, 2007.

Martínez Shaw, Carlos

"The Philippine Islands: a vital crossroad during the first globalization period", en Culture E History Digital Journal 3:1 (2014), http://dx.doi.org/10.3989/chdj.2014.004.

Martínez Shaw, Carlos y José María Oliva Melgar (eds.)

El sistema atlántico español (siglos XVII-XIX), Madrid, Marcial Pons, 2005.

McNeIL, John Robert y William Hardy McNeIL

Las redes humanas: una historia global del mundo, Barcelona, Crítica, 2004.

Oliva Melgar, José María

“«La metrópoli sin territorio». ¿Crisis del comercio de Indias en el siglo XVIII o pérdida del control del monopolio", en MARtínez Shaw y Oliva Melgar, 2005, pp. 19-74.

Ollé, Manel

La empresa de China. De la Armada Invencible al Galeón de Manila, Barcelona, Acantilado, 2002.

"La formación del Parián de Manila: la construcción de un equilibrio inestable", en SAN GINÉs, 2006, pp. 27-49.

“Zheng Zhilong (Nicolás Iquan) y Zheng Chenggong (Koxinga), en Coello de la Rosa, Burrieta Burrieza y MoreNO, 2012, pp. 65-79. 
"La proyección de Fujian en Manila: los sangleyes del Parián y el comercio de la nao de China", en Bernabéu Albert y Martínez Shaw, 2013, pp. 155-177.

Oropeza Keresey, Déborah

"La esclavitud asiática en el virreinato de la Nueva España, 1565-1673”, en Historia Mexicana, LXI:1(241) (jul.-sep. 2011), pp. 5-57.

Pomeranz, Kenneth y Topik Steven

The World that Trade Created. Society, Culture, and the World Economy. 1400 to the Present, Londres, Nueva York, M. E. Sharpe, 2006.

ReID, Anthony

Southeast Asia in the Age of Commerce, 1450-1680, Michigan, Yale University Press, 1988.

Richards, John F.

"Early Modern India and World History", en Journal of World History, 8:2 (2004), pp. 197-207.

Rojas, José Luis de

"Árboles, bosques y corsés: hechos, perspectivas e interpretaciones en la historia de América y España”, en Historia Mexicana, LXI:3 (243) (ene.-mar. 2012) pp. 1171-1209.

Ruiz Ibáñez, José Javier

"Vivir «sin dexar parte donde las cruzes españolas no hayan sido conocidas». Don Diego de Villalobos y Benavides en la administración imperial de la Monarquía Hispánica”, en Historia Mexicana, LXI:3 (243) (ene.-mar. 2012), pp. 317-378.

Ruiz Guadalajara, Juan Carlos

"En lo más dilatado de la Monarquía: Manuel Antonio de Ocio y Ocampo, la Nueva España y el horizonte filipino", en Historia Mexicana, Lxi:3 (243) (ene.-mar. 2012), pp. 849-932. 
Sachsenmaier, Dominic

Global Perspectives on Global History: Theories and Approahes in a Connected World, Nueva York, Cambridge University Press, 2011.

Sales Colín, Ostwald

"El movimiento portuario de Acapulco: un intento de aproximación (1626-1654)", en Revista Complutense de Historia de América, 22 (1996), pp. 97-119.

"Los cargazones del galeón de la carrera de poniente: primera mitad del siglo xviI", en Revista de Historia Económica. Journal of Iberian and Latin Economic History, 3 (2000), pp. 629-664.

SAn Ginés, Pedro (ed.)

La investigación sobre Asia Pacífico en España, Granada, Servicio de Publicaciones de la Universidad de Granada, 2006.

Souza, George Bryan

The Survival of Empire. Portuguese Trade and Society in China and the South China Sea (1630-1754), Cambridge, Cambridge University Press, 1986.

Spence, Jonathan y John E. Jr. Wills

From Ming to Ch'ing. Conquest, Region and Continuity in Seventeenth-Century China, Londres, Yale University Press, 1979.

SPEnce, Jonathan

“The K’ang-Hsi Reign”, en Twitchett y Fairbank, 2002, pp. 120-181.

Subrahmanyam, Sanjay

"Connected Histories: Notes Towards a Reconfiguration of Early Modern Eurasia”, en Modern Asian Studies, 31:3 (1997), pp. 735-762.

"Par-delà l'incommensurabilité: pour une histoire connecteé des empires aux temps modernes", en Revue d'histoire moderne et contemporaine, 54:4 bis (2007), pp. 34-53. 
THORTON, John

Africa and Africans in the Making of Atlantic World, 14001680, Nueva York, Cambridge University Press, 1992.

Tremml, Birgit

"The Global and the Local: Problematic Dynamics of the Triangular Trade in the Early Modern Manila”, en Journal of World History, 23:3 (2012), pp. 555-586.

Trivellato, Francesca

The Familiarity of Strangers. The Sephardic Diaspora, Livorno, and Cross-cultural Trade in the Early Modern Period, New Haven, Yale University Press, 2009.

Twitchett, Denis y John K. Fairbank

The Cambridge History of China, Cambridge, Cambridge University Press, 2002.

VALdÉs LaKowsky, Vera

"La importancia de la plata novohispana en Asia", en BARrón Sото, 2012, pp. 179-197.

Valle Pavón, Guillermina del

"Bases del poder de los mercaderes de plata de la ciudad de México. Redes, control del Consulado y de la Casa de Moneda a finales del siglo xvir", en América Latina en la bistoria económica, 27 (2006), pp. 7-48.

Varela, Consuelo

"Microhistoria de un galeón: el Santo Niño y Nuestra Señora de Guía (1684-1689)”, en Bernabéu Albert y Martínez SHAw, 2013, pp. 229-246.

Wakeman, Frederic Junior

The Great Enterprise. The Manchu Reconstruction of Imperial Order in Seventeenth-Century China, Los Ángeles, University of California Press, 1985. 
WALLERSTEIN, Immanuel

The Modern World-System I. Capitalist Agriculture and the Origins of the European World-Economy in the Sixteenth Century, Londres, Academic Press, 1974.

WILLs, John

"Interactive Early Modern Asia: Scholarship from a New Generation", en International Journal of Asia Studies, 5:2 (2008), pp. 235-245.

"Maritime China from Wang Chih to Shih Lang: Themes in Peripheral History", en Spence y Wills, 1979, pp. 201-238.

Yu-Ting Lu

Taiwán. Historia, política e identidad, Barcelona, Bellaterra, 2010.

Yuste López, Carmen

El comercio de la Nueva España con Filipinas, 1590-1785, México, Instituto Nacional de Antropología e Historia, 1985.

"Allende el mar. Los intangibles confines de la negociación mexicana en Manila durante el siglo XVIII", en LuQue TALAván y Manchado López, 2007, pp. 241-253.

"El dinamismo rutinario de la carrera transpacífica”, en BARRón Sото, 2012, pp. 199-232.

"De la libre contratación a las restricciones de la permission. La Andadura de los comerciantes de México en los giros iniciales con Manila, 1580-1610”, en Bernabéu Albert y MarTíNez SHaw, 2013, pp. 85-106. 